\title{
Ensayo cuantitativo para la determinación de la actividad hidrolítica de la enzima biotinidasa
}

\begin{abstract}
Ernesto C. González 1, Libertad Díaz 2 ${ }^{2}$, Amarilys Frómeta ${ }^{1}$, Darlenis Herrera ${ }^{1}$, Adonis Montenegro ${ }^{2}$

\footnotetext{
Laboratorio de Tamizaje Neonatal, Centro de inmunoensayo, La Habana, Cuba.
}

2 instituto de Ciencias Básicas y Preclínicas Victoria de Girón, Departamento de Inmunología, La Habana, Cuba.

El presente trabajo describe la estandarización de un ensayo diseñado para cuantificar la actividad hidrolítica de la enzima biotinidasa en muestras de suero humano, el cual se basa en el método de Wolf y colaboradores, que emplea el $\mathrm{N}$-biotinil-p-aminobenzoico (BPABA) como sustrato. Con la adición de detergentes a la solución de nitrito de sodio, se eliminan las burbujas de nitrógeno formadas durante la reacción de diazotación y se mejora la precisión del ensayo. Se observó que la congelación-descongelación de las muestras de suero no afecta la actividad hidrolítica de la enzima biotinidasa. La evaluación de la interferencia de fármacos en el ensayo mostró que con el sulfametoxasol/trimetoprim y la procaína/ benzilpenicilina hay desarroilo de coior en ausencia del sustrato BPABA. Los vaiores promedio de actividad hidrolítica de la biotinidasa, obtenidos en un grupo de 205 niños sanos, fue de $7,04 \pm 2,2 \mathrm{nmol} / \mathrm{min} / \mathrm{ml}$. No se encontraron diferencias estadísticamente significativas al evaluar la actividad de la enzima por sexo, raza y grupos de edad. Este ensayo se puede emplear en la determinación de la actividad hidrolítica de la enzima biotinidasa en muestras de suero humano y, específicamente, en la confirmación de los casos detectados por los programas de tamizaje neonatal para la deficiencia de biotinidasa.
\end{abstract}

Palabras ciave: deficiencia de biotinidasa, ensayo colorimétrico, tamizaje neonatal.

\section{Quantitative assay to determine the hydrolytic activity of biotinidase}

A quantitative assay was standardized to determine the hydrolytic activity of biotinidase in human serum samples. The current Wolf et al. assay uses $\mathrm{N}$-biotinyl-p-aminobenzoic acid as substrate. The assay's precision was improved by the addition of detergents to the sodium nitrite solution. This eliminated the formation of nitrogen bubbles during the diazotation reaction. Freezing and thawing of the serum samples did not affect the hydrolytic activity. Farmaco's interference test showed positive results with sulfametoxasol/trimetoprima and procaine/ benzylpenicilline. The hydrolytic activity of biotinidase averaged $7.04 \pm 2.2 \mathrm{nmol} / \mathrm{min} / \mathrm{ml}$ in a group of 205 healthy children. No statistically significant differences in enzymatic activity was observed between variables of sex, races and age group. The standardize assay can determine the hydroiytic activity of biotinidase human serum samples and can confirm the positive cases detected by neonatal screening programs for biotinidase deficiency.

Key words: Biotinidase deficiency, colorimetric assay, neonatal screening.

Uno de los errores innatos del metabolismo de la biotina lo constituye la deficiencia de la enzima

\footnotetext{
Correspondencia:

Ernesto C. González, Apartado postal 6653, Cubanacán, Playa C, Habana, Cuba.

Recibido: 07/05/01; aceptado: 19/11/01
}

biotinidasa. Descrita en la década de los 50 , la biotinidasa es la enzima encargada del reciclaje de la biocitina obtenida de la degradación de las carboxilasas y de la liberación de la biotina unida a las proteínas de la dieta, llevándolas a una forma biológicamente viable $(1,2)$. 
La deficiencia de biotinidasa es un trastorno metabólico autosómico recesivo que se clasifica en deficiencia total $(<10 \%$ de actividad hidrolítica) o parcial (10-30\%)(3-5). El cuadro clínico y el tiempo de presentación de los síntomas es muy variable (6-10). La sintomatología inicial está relacionada con el sistema nervioso: hipotonía muscular, ataxia y retraso en el desarrollo psicomotor $(6,8)$. También puede observarse pérdida de la audición, atrofia óptica, alopecia, problemas respiratorios, dermatitis, conjuntivitis, infecciones fúngicas e inmunodeficiencias (8). Las manifestaciones bioquímicas más frecuentes son la acidosis cetoláctica y la aciduria orgánica. La descompensación metabólica puede llevar al coma y a la muerte (6). Un diagnóstico temprano en el período neonatal permite una terapia efectiva con biotina (6-8).

En 1984, se comenzó el primer programa de tamizaje neonatal de la deficiencia de biotinidasa en el estado de Virginia, Estados Unidos (11). Otros países también han desarrollado programas para el tamizaje de la enfermedad como un acto de medicina preventiva (12-21). Se estima que la incidencia mundial de la deficiencia de biotinidasa es de 1:60.000 (4). Su incidencia es baja si se compara con otras patologías conocidas como son el hipotiroidismo congénito $(1: 4.000)$ y la fenilcetonuria (1:15.000), pero es similar a otras como la galactosemia (1:60.000).

El presente trabajo describe la estandarización de un ensayo colorimétrico que permite la cuantificación de la actividad hidrolítica de la enzima biotinidasa en muestras de suero humano. La interferencia de los medicamentos de la familia de las sulfonamidas se ha informado en los ensayos para la detección de la deficiencia de biotinidasa que emplean el BPABA como sustrato. Por tanto, es importante evaluar el posible efecto de fármacos de uso común en el período neonatal y en la infancia sobre este tipo de ensayo, para disminuir la posibilidad de falsos resultados $(11,22)$.

\section{Materiales y métodos}

\section{Reactivos}

El ácido tricloroacético (TCA), el N-biotinil-paminobenzoico (B-PABA), el p-amino-benzoico
(PABA), el fosfato de potasio, el nitrito de sodio (NaNO2), el sulfato de amonio, el N-1-naftiletilendiaminodihidrocloruro (vitamina K-6) y el ácido etilendiaminatetraacético (EDTA) se obtuvieron de Sigma Chemical Co., St. Louis, U.S.A.

\section{Ensayo para determinar la actividad hidrolítica de la enzima biotinidasa en muestras de suero humano}

El ensayo se basa en una modificación al método descrito por Wolf et al. (23), en la cual se adicionan $25 \mathrm{ml}$ de suero a una mezcla de reacción compuesta por $200 \mathrm{mM}$ del sustrato B-PABA y 4,5 mM de EDTA en solución tampón fosfato de potasio, $47 \mathrm{mM}, \mathrm{pH} 6,0$ para un volumen final de $500 \mathrm{ml}$. Se empleó una curva de calibración de 5 , $10,20,40$ y $80 \mathrm{mM}$ de PABA y $4,5 \mathrm{mM}$ de EDTA en solución tampón fosfato de potasio, $47 \mathrm{mM}$, $\mathrm{pH} 6,0$. Se incubó a $37^{\circ} \mathrm{C}$ en cámara húmeda para que ocurriera la reacción enzimática. Se detuvo la reacción con $50 \mathrm{ml}$ de una solución fría de TCA $(1,84 \mathrm{M})$. Después de 10 minutos, se centrifugó a $16.000 \mathrm{~g}$; se tomaron $300 \mathrm{ml}$ del sobrenadante y se le añadieron $100 \mathrm{ml}$ de agua destilada. Luego, se adicionaron $40 \mathrm{ml}$ de los siguientes reactivos con intervalos de 3 minutos: nitrito de sodio $(14,5 \mathrm{mM})$, sulfamato de amonio $(43,8 \mathrm{mM})$ y vitamina K-6 (3,86 mM). Se esperaron 10 minutos y se transfirieron $200 \mathrm{ml}$ a placas microELISA. Se midió la densidad óptica a $546 \mathrm{~nm}$, empleando el lector de placas FluorímetroFotómetro PR 521 (Tecnología SUMA, Centro de Inmunoensayo).

La figura 1 muestra el diagrama de la reacción enzima-sustrato, los productos obtenidos y las reacciones que dan lugar a la formación del complejo coloreado.

La actividad enzimática se calculó según la siguiente fórmula:

actividad enzimática $=$ nmoles de $\mathrm{PABA}$ producidos/tiempo de incubación/volumen de muestra.

Se determinó si la adición de detergentes a la solución de nitrito de sodio eliminaba las burbujas de nitrógeno formadas durante la reacción de diazotación, las cuales interfieren en la señal obtenida de absorbancia. Se emplearon los 


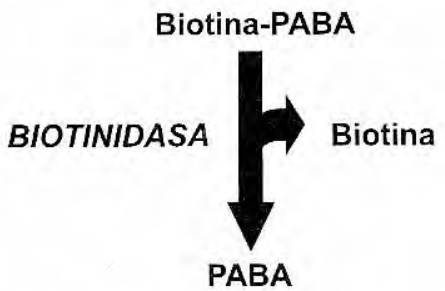

$$
\begin{array}{ll}
\mathrm{PABA}+\mathrm{NaNO}_{2}+\text { sulfamato de amonio } & \text { TCA } \\
\mathrm{PABA} \text { diazotizado + vitamina } \mathrm{k}-6 \longrightarrow \text { PABA diazotizado }+ \text { Nitrógeno }
\end{array}
$$

reacción

enzimática

Figura 1. Hidrólisis del sustrato BPABA por la enzima biotinidasa (reacción enzimática) y detección del PABA formado (reacción colorimétrica).

detergentes no iónicos tween 20 y tritón X-100, los cuales se añadieron a la solución de nitrito de sodio en concentraciones de 0,1 y $0,5 \%$.

Se estableció el tiempo óptimo de incubación del ensayo y se evaluaron los valores promedio de absorbancia obtenidos con los diferentes puntos de la curva de PABA $(n=5)$ y con una muestra de suero humano con actividad normal de biotinidasa $(n=5)$. Los tiempos estudiados fueron $0,10,20$, $30,60,90$ y 120 minutos y se determinó como óptimo el tiempo a partir del cual no variaba la señal obtenida de absorbancia.

Se evaluó la interferencia con la reacción colorimétrica de los siguientes fármacos: sulfametoxasol/trimetoprim, ampicilina, gentamicina, fenobarbital y estreptomicina a concentraciones de $0,625,1,25,2,5,5$ y $10 \mathrm{mg} / \mathrm{ml}$ y de procaína/benzilpenicilina a 188, 375, 750, 1.500 y 3.000 unidades internacionales (UI). Se empleó un suero humano libre de actividad de la enzima biotinidasa al que se le adicionaron los fármacos. En este ensayo, las muestras se incubaron con el tampón fosfato en sustitución del sustrato.

Se estudió la interferencia de fármacos en muestras de niños que estaban recibiendo medicamentos en el momento de la toma de la muestra. Este ensayo se realizó incubando simultáneamente las muestras con tampón fosfato y con la solución sustrato.

Se estudió el efecto de eventos repetidos de congelación-descongelación de las muestras de suero humano sobre la actividad hidrolítica de la enzima biotinidasa. Las muestras se sometieron a 5 ciclos de congelación a $-35^{\circ} \mathrm{C}$ durante 30 minutos y descongelaciones a temperatura ambiente. Se calculó la actividad enzimática de la biotinidasa para cada uno de los ciclos de congelación-descongelación.

Para la determinación de los coeficientes de variación $(\mathrm{CV})$ intra e interensayo, se evaluaron muestras de actividad conocida de biotinidasa. El CV se definió como la división entre la desviación estándar y el valor promedio de cada muestra, multiplicado por 100 .

Se determinaron los porcentajes de recuperación obtenidos para el ensayo al mezclar muestras de suero humano con actividad biotinidasa conocida. El porcentaje de recuperación se definió como la división entre la actividad biotinidasa obtenida y la actividad esperada, multiplicado por 100.

\section{Determinación de la actividad hidrolítica de la biotinidasa en muestras de suero humano}

Se emplearon muestras de suero de un grupo de niños $(n=205)$ con edades comprendidas entre 1 y 17 años, a quienes se les habían ordenado ensayos clínicos de rutina. Estas muestras se obtuvieron en el Laboratorio de Bioquímica del Hospital Pediátrico de Centro Habana, Ciudad de La Habana, Cuba. Los niños presentaban enfermedades frecuentes en esta etapa de la vida (influenza, enfermedades diarreicas) cuyos signos clínicos excluyen desórdenes neurológicos y 
metabólicos que puedan asociarse con la deficiencia de biotinidasa.

\section{Análisis estadístico}

Para el análisis estadístico de los datos se utilizó el programa Statistics for Windows, versión 4.5. Para evaluar la influencia del proceso de congelación-descongelación sobre la actividad de la biotinidasa en muestras de suero humano, se utilizó un análisis de varianza (ANOVA) de clasificación simple. En la comparación de los valores promedios de actividad hidrolítica de la enzima biotinidasa, obtenidos por sexo, raza y grupos de edad se empleó la prueba t de Student. Con ambos datos estadísticos se trabajó para un nivel de significación de $p<0,05$.

\section{Resultados y discusión}

Evaluación de la adición de detergentes a la solución de nitrito de sodio y determinación del tiempo óptimo de incubación del ensayo

En la figura 2 se muestran los valores promedio de absorbancia obtenidos para cada punto de la curva de PABA al evaluar la adición de los detergentes no iónicos tritón X-100 y tween 20 a la solución de nitrito de sodio, con el objetivo de eliminar las burbujas de nitrógeno formadas durante la reacción de diazotación y que pudieran interferir en la medición de la absorbancia.

Los altos valores de absorbancia para la condición en la cual no se adicionó ningún detergente están asociados con las interferencias provocadas por la presencia de las burbujas en la solución. No se observaron grandes diferencias en los valores promedios de absorbancia obtenidos entre todas las condiciones donde se adicionó detergente. Sin embargo, la evaluación visual mostró que sólo se eliminaban completamente las burbujas de nitrógeno en la solución empleando el nitrito de sodio que contenía tritón $\mathrm{X}-100$ al $0,1 \%$. Este detergente en concentraciones entre 0,1 y $0,5 \%$ no afectó la actividad de la enzima y ya había sido empleado en el tampón sustrato (24). Con la adición de este detergente a la solución de nitrito de sodio, se mejoraron los valores de absorbancia que se obtienen para el calibrador de concentración de PABA igual a 0 . Esto garantiza una mejor separación entre los dos primeros puntos de la curva de calibración y mejora la precisión del ensayo.

El cuadro 1 muestra los valores de absorbancia obtenidos al incubar a $37^{\circ} \mathrm{C}$ la curva de PABA a diferentes tiempos. El tiempo de incubación no afectó los valores de absorbancia obtenidos para las diferentes concentraciones de la curva de calibración y se obtuvo una buena correlación $(0,999)$ entre todos los tiempos estudiados.

Se evaluó el efecto del tiempo de incubación sobre los valores promedio de absorbancia obtenidos con una muestra de suero humano con actividad normal de biotinidasa. Los resultados se pueden observar en la figura 3.

A partir de los 60 minutos de incubación de las muestras con la solución sustrato, se obtuvieron valores de absorbancia que no variaron con el tiempo de incubación. Estos valores de absorbancia se encuentran en una zona media de la curva de PABA lo cual nos permite hacer una buena discriminación entre las muestras de individuos afectados con la enfermedad e individuos con actividad normal de biotinidasa.

A partir de estos resultados, se decidió emplear en el ensayo un tiempo de incubación de 60 minutos. La absorbancia se pudo medir en el lector fluorímetro-fotómetro PR 521, 10 minutos después del desarrollo de color y se observó que esta señal era estable durante dos horas si se mantenían las placas protegidas de la luz.

\section{Precisión y exactitud}

En el cuadro 2 se muestran los coeficientes de variación $(\mathrm{CV})$ intra e interensayo. En ambos casos se evaluaron muestras de actividad de biotinidasa conocida y que abarcaban un amplio intervalo de la curva de calibración del ensayo. En todos los casos, los coeficientes de variación fueron inferiores al $10 \%$.

Los porcentajes de recuperación obtenidos para el ensayo al mezclar muestras de suero humano con actividad de biotinidasa conocida, fueron de $98,3 \pm 7,5 \%$ y los porcentajes individuales oscilaron entre 94 y $108 \%$.

Los resultados anteriores nos permiten plantear que el ensayo es preciso y exacto dentro de un 
intervalo que garantiza poder diferenciar poblaciones con diferentes valores de actividad de la enzima biotinidasa.

\section{Determinación del límite de detección}

El límite de detección del ensayo se definió como el valor promedio de absorbancia del calibrador 0 de la curva de calibración más tres desviaciones estándar. La actividad mínima detectable fue de $0,64 \mathrm{nmol} / \mathrm{min} / \mathrm{ml}$. Este valor de actividad nos permite utilizar el ensayo para evaluar la actividad de la enzima biotinidasa en poblaciones normales

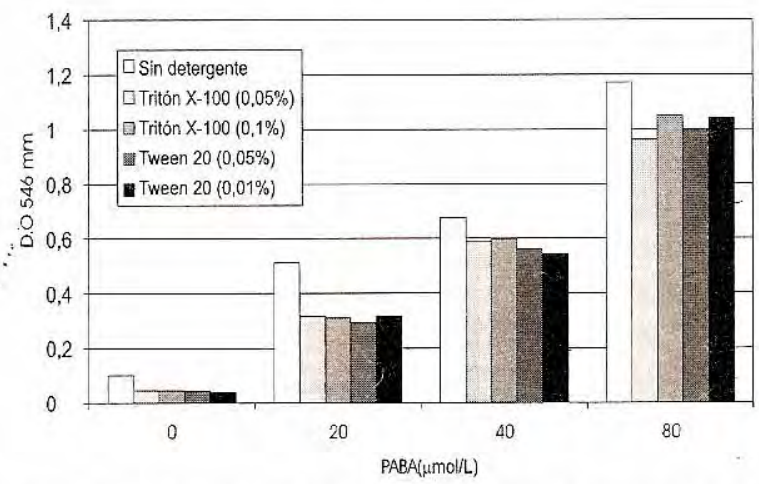

Figura 2. Comparación de los valores promedio de absorbancia $(n=5)$ obtenidos para los puntos de la curva de $\mathrm{PABA}$ al emplear detergentes en la solución de nitrito de sodio. y clasificar la deficiencia en total o parcial. La deficiencia total se informa para valores de actividad inferiores a $0,7 \mathrm{nmol} / \mathrm{min} / \mathrm{ml}$ y la deficiencia parçial en un rango de actividad entre $0,7: y \quad 2,1 \mathrm{nmol} / \mathrm{min} / \mathrm{ml}$. Los heterocigóticos obligados muestran una actividad enzimática entre 2,2 y $5,2 \mathrm{nmol} / \mathrm{min} / \mathrm{ml}(24)$.

\section{Pruebas de interferencia}

En ausencia de sustrato no hubo interferencia en las muestras de suero a las que se le adicionaron las diferentes concentraciones $(0-10 \mathrm{mg} / \mathrm{ml})$ de

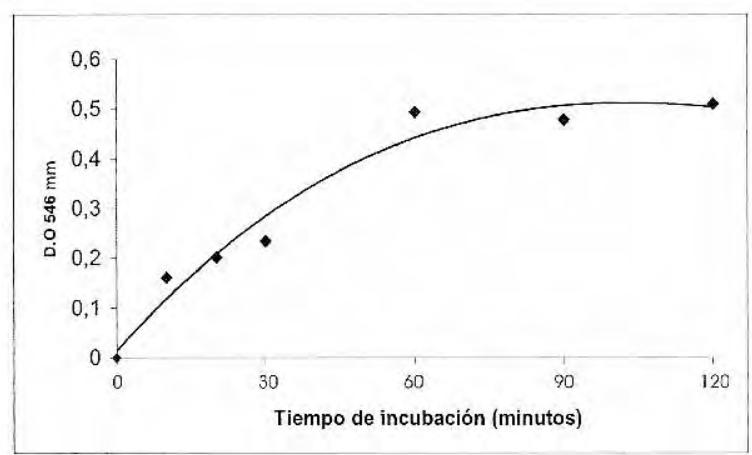

Figura 3. Efecto del tiempo de incubación sobre los valores de absorbancia en una muestra de suero humano con actividad normal de la enzima biotinidasa.

Cuadro 1. Valores promedio de absorbancia de la curva de PABA a diferentes tiempos de incubación.

\begin{tabular}{|c|c|c|c|c|c|c|c|c|}
\hline $\begin{array}{l}\text { Curva } \\
(\mu \mathrm{mol} / \mathrm{ml})\end{array}$ & er. & & & Tiempo & & & & \\
\hline & 0 & 10 & 20 & 30 & 60 & 90 & 120 & CV \\
\hline 0 & 0,049 & 0,045 & 0,048 & 0,047 & 0,045 & 0,046 & 0,046 & 3,2 \\
\hline 5 & 0,110 & 0,099 & 0,103 & 0,108 & 0,110 & 0,106 & 0,102 & 4,0 \\
\hline 10 & 0,176 & 0,160 & 0,175 & 0,171 & 0,169 & 0,177 & 0,178 & 3,7 \\
\hline 20 & 0,272 & 0,296 & 0,307 & 0,298 & 0,297 & 0,308 & 0,310 & 4,3 \\
\hline 40 & 0,541 & 0,537 & 0,554 & 0,562 & 0,560 & 0,544 & 0,560 & 1,8 \\
\hline 80 & 0,980 & 0,941 & 0,985 & 0,982 & 1,014 & 0,983 & 0,961 & 2,3 \\
\hline
\end{tabular}

CV: coeficiente de variación para cada punto de la curva

Cuadro 2. Precisión del ensayo.

\begin{tabular}{cccccc}
\hline $\begin{array}{c}\text { Actividad enzimática } \\
\text { (nmol/min/ml) }\end{array}$ & $\begin{array}{c}\text { Desviación } \\
\text { estándar }\end{array}$ & $\begin{array}{c}\text { CV } \\
\text { intraensayo } \\
(\mathbf{n}=\mathbf{2 0})\end{array}$ & $\begin{array}{c}\text { Actividad enzimática } \\
(\mathbf{n m o L} / \mathbf{m i n} / \mathbf{m})\end{array}$ & $\begin{array}{c}\text { Desviación } \\
\text { estándar }\end{array}$ & $\begin{array}{c}\text { CV } \\
\text { interensayo } \\
(\mathbf{n}=\mathbf{1 0})\end{array}$ \\
\hline 2,61 & 0,20 & 7,7 & 4,1 & 0,31 & 7,5 \\
5,71 & 0,29 & 5,1 & 6,0 & 0,31 & 5,9 \\
10,12 & 0,67 & 6,6 & 8,5 & 0,70 & 7,8 \\
\hline
\end{tabular}


ampicilina, gentamicina, fenobarbital y estreptomiciná. Los valores de absorbancia obtenidos fueron similares al valor del calibrador 0 del ensayo, que fue de 0,09. Los sueros que contenían sulfametoxasol/trimetoprim y procaína/benzilpenicilina sí interfirieron.en el ensayo. Estos resultados se muestran en el cuadro 3 . El valor de absorbancia del calibrador de $80 \mu \mathrm{M}$ de la curva de calibración de PABA fue de 1,25. Con el sulfametoxasol/trimetoprim, para todas las concentraciones estudiadas, los valores de absorbancia fueron superiores al valor del calibrador de $80 \mu \mathrm{M}$ de PABA. En el caso de la procaína/benzilpenicilina, los valores de absorbancia disminuyeron a partir de $750 \mathrm{UI}$, aunque todavía a la concentración de 188 Ul esos valores de absorbancia interfirieron en el ensayo.

Entre las muestras provenientes del Hospital Pediátrico de Centro Habana se encontraron 5 niños que estaban en tratamiento con sulfametoxasol/trimetoprim. En el cuadro 4 se observan los valores de absorbancia y de actividad enzimática calculada para esas muestras, antes y después de corregida la posible interferencia con el fármaco. Esta corrección se realizó teniendo en cuenta la absorbancia obtenida con las muestras en ausencia de sustrato. En las muestras
1, 2 y 3 se observó la interferencia del fármaco, lo que hace que en todos los casos la actividad real de la enzima sea mucho menor. Al ser corregida la actividad enzimática en las muestras 2 y 3 pudimos observar que los niños que presentaban una actividad de biotinidasa por encima del valor promedio de la población $(7,1 \mathrm{nmol} / \mathrm{min} / \mathrm{ml})$, realmente clasificaban dentro del grupo de heterocigóticos obligados (24). Las muestras 4 y 5 no mostraron señales de interferencia, pues los valores de absorbancia obtenidos en ausencia de sustrato son similares a los del calibrador 0 de la curva de PABA $(0,045)$. La ausencia de interferencia en las dos últimas muestras puede deberse a que, en el momento de la toma de la muestra, el fármaco ya había sido metabolizado por el organismo. No se pudieron precisar en ninguno de los casos las dosis y el tiempo de tratamiento.

Se conocía de la interferencia producida por los medicamentos pertenecientes a la familia de las sulfonamidas $(11,22)$. En el caso de la procaina/ benzilpenicilina la interferencia se debe al grupo 4-aminobenzoico en la estructura de la procaína. En ambos medicamentos, la interferencia está asociada con la similitud estructural del fármaco con el PABA. La presencia de grupos aminos

Cuadro 3. Valores promedio de absorbancia obtenidos con los sueros a los que se les adicionaron los medicamentos sulfametoxasol/trimetoprim y procaina/benzilpenicilina.

\begin{tabular}{cccc}
\hline $\begin{array}{c}\text { Sulfametoxasol/trimetoprim } \\
(\mathbf{m g} / \mathbf{m l})\end{array}$ & $\begin{array}{c}\text { Absorbancia } \\
(\mathbf{5 4 6} \mathbf{~ n m}) \\
\mathbf{n = 5}\end{array}$ & $\begin{array}{c}\text { Procaina/benzilpenicilina } \\
\text { UI }\end{array}$ & $\begin{array}{c}\text { Absorbancia } \\
\mathbf{( 5 4 6} \mathbf{n m}) \\
\mathbf{n = 5}\end{array}$ \\
\hline 10,0 & 3,00 & 3.000 & 2,88 \\
5,0 & 2,99 & 1.500 & 1,81 \\
2,5 & 2,25 & 750 & 0,66 \\
1,25 & 2,18 & 375 & 0,64 \\
0,625 & 1,53 & 188 & 0,27 \\
\hline
\end{tabular}

Cuadro 4. Interferencia del sulfametoxasol/trimetoprim en la determinación de la actividad de biotinidasa en muestras de niños.

\begin{tabular}{cccccc}
\hline Muestras & $\begin{array}{c}\text { Absorbancia } \\
\text { total }\end{array}$ & $\begin{array}{c}\text { Actividad enzimática } \\
\text { total } \\
\text { (nmol/min/ml) }\end{array}$ & $\begin{array}{c}\text { Absorbancia } \\
\text { sin sustrato }\end{array}$ & $\begin{array}{c}\text { Absorbancia } \\
\text { corregida }\end{array}$ & $\begin{array}{c}\text { Actividad enzimática } \\
\text { corregida } \\
\text { (nmol/min/ml) }\end{array}$ \\
\hline 1 & 0,55 & 13,4 & 0,18 & 0,37 & 8,58 \\
2 & 0,46 & 10,6 & 0,26 & 0,20 & 3,90 \\
3 & 0,42 & 10,0 & 0,24 & 0,18 & 3,39 \\
4 & 0,37 & 8,6 & 0,05 & 0,32 & 7,70 \\
5 & 0,28 & 6,1 & 0,03 & 0,25 & 5,44 \\
\hline
\end{tabular}


primarios en la estructura aromática de estos fármacos contribuye a la formación del complejo coloreado aún en ausencia de la enzima biotinidasa. Los estudios que se han realizado no han analizado las condiciones farmacológicas de biodisponibilidad y degradación del medicamento $(11,22)$, lo que no descarta la posibilidad de que algunos de sus metabolitos puedan generar otros interferentes.

Los fármacos evaluados son de uso común en el período neonatal y en la infancia en general, por lo que estos estudios de interferencia son un elemento muy importante a tener en cuenta al emplear este ensayo, ya que la presencia de ciertos fármacos puede ser una fuente de falsos negativos $y$, en aquellos casos en que se obtengan valores de absorbancia muy altos, se debe sospechar la presencia de interferentes. De hecho, se recomienda realizar las dos determinaciones simultáneamente (en ausencia y presencia de sustrato) para descartar posibles interferencias $(11,22)$.

\section{Efecto de la congelación-descongelación sobre la actividad enzimática}

El cuadro 5 muestra los resultados obtenidos al evaluar el efecto de la congelación-descongelación sobre la actividad enzimática de la biotinidasa en cinco muestras de suero humano. El proceso de congelación-descongelación no afectó significativamente la actividad de la enzima biotinidasa.

En este trabajo nos referimos a la actividad hidrolítica de la enzima, pues es la única función que se puede medir con el ensayo. Por tanto, no podemos afirmar que las otras funciones de la enzima biotinidasa, por ejemplo, la actividad biotiniltransferasa (24), no se vean afectadas por el proceso de congelación-descongelación. Hay que señalar que este estudio se realizó con muestras recientes, por lo que seria interesante evaluar este efecto con muestras conservadas por largos períodos a diferentes temperaturas.

\section{Determinación de la actividad de la enzima biotinidasa en muestras de suero humano}

El valor promedio de actividad hidrolítica de la enzima biotinidasa obtenido al evaluar un grupo
Cuadro 5. Efecto de la congelación-descongelación de las muestras de suero humano sobre la actividad de la biotinidasa; para el análisis estadístico se empleó un análisis de varianza (ANOVA) de clasificación simple.

\begin{tabular}{ccccccc}
\hline $\begin{array}{l}\text { Actividad } \\
\text { enzimática } \\
\text { (nmol/min/ml) }\end{array}$ & $\mathbf{1}$ & $\mathbf{2}$ & $\mathbf{3}$ & $\mathbf{4}$ & $\mathbf{5}$ & $\boldsymbol{p}$ \\
\hline 6,831 & 7,662 & 7,119 & 7,198 & 7,825 & 7,881 & 0,07 \\
5,731 & 6,450 & 5,925 & 6,631 & 5,650 & 6,756 & 0,27 \\
7,037 & 7,938 & 7,413 & 8,288 & 8,913 & 7,800 & 0,10 \\
5,631 & 6,869 & 6,313 & 5,756 & 6,381 & 6,788 & 0,11 \\
6,163 & 7,356 & 6,856 & 7,662 & 7,006 & 7,813 & 0,19 \\
\hline
\end{tabular}

de niños ( $n=205)$, con un promedio de edad de $6,5 \pm 4,2$ años, fue de $7,04 \pm 2,2 \mathrm{nmol} / \mathrm{min} / \mathrm{ml}$. Este resultado es similar a lo informado para otras poblaciones con actividad normal de la enzima $(25,26)$.

No se encontraron diferencias estadísticamente significativas entre los valores promedios de actividad de la enzima al realizar el estudio por sexo $(p=0,33)$ y raza $(p=0,38)$. La deficiencia de biotinidasa ha sido descrita en distintas poblaciones y no se ha determinado la existencia de una mayor frecuencia de aparición por sexo o raza.

En el cuadro 6 se pueden observar los valores de actividad enzimática obtenidos para tres grupos de edad diferentes. El valor medio de actividad de biotinidasa obtenido para el grupo 1 fue ligeramente mayor que en el resto de los grupos; sin embargo, no hubo diferencias estadísticamente significativas al realizar la prueba $t$ de Student entre los grupos 1 y $2(p=0,11)$, los grupos 1 y $3(p=0,21)$ y los grupos 2 y $3(p=0,94)$.

Se ha informado que los niveles de actividad de biotinidasa en recién nacidos es entre 50 y $70 \%$ inferior al valor promedio de la población adulta (22); pero los niveles de actividad en adultos se alcanzan al mes de nacidos (27). Esto coincide con nuestros resultados, en los cuales el valor medio de actividad de biotinidasa por grupos de edad es similar a lo informado para la población adulta. Los valores de actividad enzimática obtenidos con las muestras 2 y 3 (cuadro 4), que los define como heterocigóticos obligados, hablan de la necesidad de realizar estudios que permitan evaluar la frecuencia de portadores de genes para 
Cuadro 6. Estudio de la actividad hidrolítica de la enzima biotinidasa por grupos de edad; para el análisis estadistico se empleó la prueba t de Student.

\begin{tabular}{|c|c|c|c|}
\hline Grupos & $\begin{array}{l}\text { Edad } \\
\text { (años) }\end{array}$ & $\mathrm{n}$ & $\begin{array}{l}\text { Actividad } \\
\text { enzimática } \\
(\mathrm{nmol} / \mathrm{min} / \mathrm{ml})\end{array}$ \\
\hline 1 & $1-5$ & 95 & $7,27 \pm 2,13$ \\
\hline 2 & $6-10$ & 69 & $6,75 \pm 2,06$ \\
\hline 3 & $11-17$ & 41 & $6,78 \pm 2,09$ \\
\hline
\end{tabular}

Datos expresados: media \pm D.E.

la deficiencia de biotinidasa en la población cubana. Estimados internacionales obtenidos de los programas de tamizaje neonatal muestran una frecuencia de portadores de 1 por cada 123 individuos (28).

La incidencia de la deficiencia de biotinidasa en muchos países es desconocida. Según los resultados de los programas de tamizaje neonatal, la incidencia de la deficiencia total es aproximadamente de 1 en $110.000 \mathrm{y}$, teniendo en cuenta los casos de deficiencia parcial, se estima una incidencia mundial de 1 en 60.000 (4). El diagnóstico temprano de esta enfermedad mediante los programas de tamizaje neonatal, así como una efectiva suplementación oral con biotina libre, previene la aparición de síntomas.

Este ensayo colorimétrico cuantitativo que emplea como sustrato el B-PABA tiene la ventaja de emplear pequeños volúmenes de muestra $(25 \mathrm{ml}$ de suero) sin que se afecte la precisión y exactitud $(29,30)$ y puede utilizarse dentro de los programas de tamizaje neonatal para la confirmación y clasificación de los casos en que se sospeche la deficiencia de biotinidasa. Además, puede emplearse en la realización de estudios familiares y en el análisis de individuos que presenten algunos de los síntomas de la enfermedad.

\section{Referencias}

1. Nyhan WL. Inborn errors of biotin metabolism. Arch Dermatol 1987;123:1696-8.

2. Thomas RW, Peterson WH. The enzimatic degradation of soluble bound biotin. J Biol Chem 1954;210:56979.

3. Wolf B, Grier RE, Allen RJ, Goodman SI, Kien CL. Biotinidase deficiency: the enzimatic defect in late-onset multiple carboxylase deficiency. Clin Chim Acta 1983; 131:273-81.
4. Wolf B. Disorders of biotin metabolism. En: Scriver CR, Beaudet AL, Sly WS, Valle D, editors. The metabolic and molecular bases of inherited disease. New York: McGraw-Hill, Inc; 1995. p.3151-80.

5. Pomponio RJ, Hymes J, Reynolds TR, Meyers GA, Fleischhauer K, Buck GA, et al. Mutations in the human biotinidase gene that cause profound biotinidase deficiency in symptomatic children: molecular, biochemical, and clinical analyses. Pediatr Res 1997;42:840-8.

6. Wolf B, Grier RE, Allen RJ, Goodman SI, Kien CL, Parker WD, et al. Phenotypic variation in biotinidase deficiency. J Pediatr 1983;103:233-7.

7. Wolf B, Heard GS, Jefferson LG, Proud VK, Nance WE, Weissbecker KA. Clinical findings in four children with biotinidase deficiency detected through a statewide neonatal screening program. N Engl J Med 1985;313: 16-9.

8. Wastell HJ, Bartlett K, Dale G, Shein A. Biotinidase deficiency: a survey of 10 cases. Arch Dis Child 1988;63: 1244-9.

9. Lott IT, Lottenberg S, Nyhan WL, Buchsbaum MJ. Cerebral metabolic changes after treatment in biotinidase deficiency. J Inherit Metab Dis 1993;16:399-407.

10. Collins JE, Nicholson NS, Dalton N, Leonard JV. Biotinidase deficiency: early neurological presentation. Dev Med Child Neurol 1994;36:263-70.

11. Heard GS, McVoy JR, Wolf B. A screening method for biotinidase deficiency in newborns. Clin Chem 1984;30: 125-7.

12. Minns RA, Kirk J. Biotinidase deficiency in Scotland. Dev Med Child Neurol 1994; 36:748-9.

13. Castiñeiras DE, Couce ML, Alonso-Fernández JR. Two cases of biotinidase deficiency within a 9 day period after 8 years of neonatal screening involving the analysis of 175,000 newborn children. En: Levy HL, Hermos RJ, Grady GF, editors. Proceedings, Third Meeting of the International Society for Neonatal Screening, 1996, Oct. 20-23. Boston: New England Regional Newborn Screening Program; 1996. p.190-1.

14. Pistaccio LG, Castillo PI, Di Carlo CM, Adam MM, Lanz MH, Gómez FR, et al. Primera experiencia de pesquisa masiva de deficiencia de biotinidasa en Argentina. En: Cornejo V, Raimann E, Colombo M, editores. Resúmenes, II Congreso Latinoamericano de Errores Innatos del Metabolismo y Pesquisa Neonatal, 1999, oct. 24-27. Santiago de Chile: Caupolicán Servicios Gráficos; 1999. p.83.

15. Héron B, Gautier A, Dulac O, Ponsot G. Déficit en biotinidase. Une encéphalopathie progressive curable par la biotine. Arch Fr Pediatr 1993;50:875-8.

16. Möslinger D, Scheibeneiter S, Mühl A, Suormala $\mathrm{T}$, Baumgartner $\mathrm{R}$, Tiefenthaler $\mathrm{M}$, et al. 12 years newborn screening for biotinidase deficiency in Austria. 
Abstracts, 4th Meeting of the International Society for Neonatal Screening 1999, June 13-16. Oslo: Stockholm Convention Bureau; 1999. p.109.

17. Pomponio RJ, Yamaguchi A, Arashima S, Hymes J, Wolf B. Mutation in a putative glycosylation site (N489T) of biotinidase in the only known japanese child with biotinidase deficiency. Mol Gen Metabol 1998; 64:152-4.

18. Tokatli A, Coskun T, Özalp I. Biotinidase deficiency with neurological features resembling multiple sclerosis. $\mathrm{J}$ Inher Metab Dis 1997;20:707-8.

19. Eyskens F. Neonatal screening for biotinidase deficiency: a success story. Abstracts, 4th Meeting of the International Society for Neonatal Screening 1999 June 13-16. Oslo: Stockholm Convention Bureau; 1999 p. 110 .

20. Guthenberg C, Holme E, Hagenfeldt L. Screening for biotinidase deficiency in Sweden. En: Levy $\mathrm{HL}$ Hermos RJ, Grady GF, editors. Proceedings, Third Meeting of the International Society for Neonatal Screening 1996, Oct. 20-23. Boston: New England Regional Newborn Screening Program; 1996. p.192.

21. Neto EC, Schulte J, Lewis E, Brites A, Giugliani R. Screening for biotinidase deficiency in South Brazil. Abstracts, 4th Meeting of the International Society for Neonatal Screening 1999, June 13-16. Oslo: Stockholm Convention Bureau; 1999.p.108.

22. Heard GS, Wolf B, Jefferson LG, Weissbecker KA, Nance WE, McVoy JRS, et al. Neonatal screening for biotinidase deficiency: results of a 1-year pilot study. $J$ Pediatr 1986;108:40-6.

23. Wolf B, Grier RE, Allen RJ, Goodman SI, Kien CL. Biotinidase deficiency: the enzimatic defect in late-onset multiple carboxylase deficiency. Clin Chim Acta 1983; 131:273-81.

24. Hymes J, Fleischhauer K, Wolf B. Biotinidase in serum and tissues. Methods Enzymol 1997;279:422-34.

25. Burton BK, Roach ES, Wolf B, Weissbecker KA. Sudden death associated with biotinidase deficiency. Pedriatics 1987;79:482-3.

26. Lawler MG, Frederick DL, Rodríguez-Anza S, Wolf $B$, Levy HL. Newborn screening for biotinidase deficiency: pilot study and follow-up of identified cases. Screening 1992;1:37-47.

27. Sourmala T, Wick H, Baumgartner ER. Low biotinidase activity in plasma of some pre-term infants: possible source of false-positive screening results. Eur J Pediatr 1988;147:478-90.

28. Wolf B, Heard GS. Disorders of biotin metabolism. En: Scriver CR, Beaudet AL, Sly WS, Valle D, editors. The metabolic basis of inherited disease. New York: McGraw- Hill, Inc; 1989. p.2083-103.

29. Wastell H, Dale G, Bartlett K. A sensitive fluorimetric rate assay for biotinidase using a new derivate of biotin, biotinyl-6-aminoquinoline. Ann Biochem 1984;140:69-73.

30. Ebrahim H, Dakshinamurti K. A fluorometric assay for biotinidase. Ann Biochem 1986;154:282-6. 


\title{
REVISIÓN DE TEMA
}

\section{Infecciones por Haemophilus influenzae en la población pediátrica}

\author{
Camilo Enrique Gutiérrez \\ División Centro Control de Enfermedades, Instituto Nacional de Salud, Bogotá, D.C., Colombia
}

\begin{abstract}
Haemophilus influenzae es un microorganismo causante de una variada gama de patologías en diferentes segmentos de la población, especialmente en la población pediátrica, en la cual representa una carga importante en morbilidad, mortalidad y gastos en salud a nivel mundial. Las infecciones por este agente cubren un gran espectro que va desde colonización asintomática del tracto respiratorio superior, infecciones superficiales y localizadas hasta afecciones sistémicas graves como sepsis, meningitis o epiglotitis. Se hace una revisión actualizada de la infección por $\mathrm{H}$. influenzae, con especial énfasis en los aspectos microbiológicos, de su patogenia, la epidemiología, los procedimientos de diagnóstico y de tratamiento, y se incluyen algunos comentarios sobre las enfermedades especificas causadas por este agente patógeno, mencionando, también, las estrategias de prevención y el impacto de la vacunación contra este agente.
\end{abstract}

Palabras clave: $H$. influenzae, infección, enfermedad invasora, factores de riesgo, vacunas.

Haemophilus influenzae infections in children

Haemophilus influenzae is the causative agent for a variety of diseases, especially among children, and exacts an important human toll in terms of morbidity, mortality and health-related expenses. Infections caused by this agent can range from asymptomatic colonization of the upper respiratory tract - including superficial and localized infections - to severe systemic complications such as sepsis, meningitis or epiglottitis. Aspectos of this disease reviewed include the following: (1) microbiological aspects, pathogenesis, epidemiology, (2) diagnostic procedures and treatment, (3) specific diseases caused by this agent, and (4) prevention strategies and the impact of vaccination.

Key words: H. influenzae, infection, invasive disease, risk factors, vaccines.

Haemophilus influenzae es un microorganismo causante de una variada gama de patologías, especialmente en la población pediátrica, en la cual representa una carga importante en morbilidad, mortalidad y gastos en salud a nivel mundial. Las infecciones por este agente cubren un gran espectro que va desde colonización asintomática del tracto respiratorio superior e infecciones superficiales y localizadas, hasta afecciones sistémicas graves como meningitis o epiglotitis (1). Su alta incidencia en algunos sectores de la población y su capacidad para

Correspondencia:

camilogut@hotmail.com

Recibido: 23/03/01; aceptado: 06/07/01 producir enfermedades graves, sumado a la posibilidad actual de tratamiento y prevención eficaz por medio de la vacunación, hacen de este agente uno de creciente importancia dentro de la práctica actual en las áreas de medicina, bacteriología y salud pública, entre otras.

El propósito de este artículo es presentar, después de una revisión actualizada de la literatura mundial, los principales aspectos microbiológicos, epidemiológicos y fisiopatológicos de la enfermedad por $\mathrm{H}$. influenzae, y el estado del arte en los métodos de diagnóstico, tratamiento y prevención de la enfermedad por este agente, haciendo énfasis en su incidencia epidemiológica sobre la población colombiana. De igual manera, se resalta la importancia de la vacunación y su 
impacto a nivel mundial y, especialmente, en Colombia.

El microorganismo fue observado por primera vez en 1882 por Robert Koch en un exudado conjuntival y lo denominó Haemophilus aegypticus o bacilo de Koch-Weeks. Posteriormente, fue aislado por Richard Pfeiffer en 1892 en el esputo y en el tejido pulmonar de pacientes infectados durante la pandemia de influenza ocurrida dos años antes, por lo que fue inicialmente denominado bacillus Pfeiffer (2). Sólo hasta la pandemia de influenza de 1918-1919 se reconoció la bacteria como parte de la flora normal del tracto respiratorio superior y no como el agente causal de la influenza, como se pensaba hasta entonces. En 1920, Winslow y sus asociados cambiaron el nombre del microorganismo a Haemophilus influenzae, debido a sus características especiales de cultivo, específicamente su requerimiento de factores $X y$ $V$ (ambos presentes en eritrocitos y liberados por lisis de esas células), lo que llevó al nombre de Haemophilus, que significa "amante de la sangre", e influenzae por su tradicional relación con la influenza (3). En 1931, Margaret Pittman definió las características de las cepas capsuladas y no capsuladas de $H$. influenzae y distinguió entre las capsuladas seis serotipos antigénicamente diferentes que denominó con letras de la "a" a la "f" (4). Además, explicó algunas características específicas del serotipo b, lo cual llevó a las primeras terapias con antisuero equino $y$, posteriormente, de conejo para tratar infecciones por $H$. influenzae tipo b $(5,6)$. Hasta 1933 , cuando se descubrió el agente de la influenza, se le consideró como agente causal de esta enfermedad. Desde entonces, se acepta que $H$. influenzae es un invasor secundario en esta enfermedad.

En las últimas décadas se han desarrollado otros sistemas más finos de caracterización taxonómica para los aislamientos de $\mathrm{H}$. influenzae, entre los cuales se destaca la tipificación basada en los perfiles de movilidad electroforética de un gran número de enzimas metabólicas, la subtipificación de acuerdo con el perfil electroforético de las proteinas de membrana externa y aquéllos basados en la heterogenicidad de los lipooligosacáridos (7). La investigación en biología molecular se ha centrado en la identificación de las proteínas de la membrana externa, P1 a P6, las cuales se estudian como variables antigénicas que podrían considerarse blanco para la elaboración de vacunas $(8,9)$. De igual manera, se realiza la caracterización de adhesinas, proteasas y otras proteínas constitutivas (10), y la caracterización de aislamientos específicos a través de procedimientos como la electroforesis en campo pulsado (11), para determinar patrones de invasividad y respuesta antigénica del hospedero (12), y el aislamiento de locus genéticos a través de medios como el multiplex PCR modificado con polimerasa AmpliTaq Gold $(13,14)$, que permite el análisis y modificación por disrupción génica de los productos transcripcionales, la identificación de mecanismos de resistencia antibacteriana y el desarrollo de nuevas herramientas contra este agente patógeno $(15,16)$.

El manejo reciente de $H$. influenzae se ha centrado en la prevención, básicamente con el desarrollo de nuevas vacunas.

\section{Microbiología}

$H$. influenzae es un cocobacilo Gram negativo pequeño $(1 \times 0,3 \mathrm{~mm})$, no móvil, no esporulado, que aparece filamentoso o pleomórfico en especímenes clínicos, lo cual puede dificultar en ocasiones su diagnóstico y que crece mejor en atmósfera microaerofilica. Sus colonias son usualmente granulares, transparentes o ligeramente opacas, circulares, con forma de domo y presentan un olor característico (17). Su cultivo se realiza en medios enriquecidos con eritrocitos lisados por calor (agar chocolate) o por degradación peptídica (medio de Fildes); para su desarrollo, requiere de una temperatura de $35^{\circ} \mathrm{C}$ y una atmósfera de 5 a $10 \%$ de $\mathrm{CO}_{2}(18)$. Para su crecimiento in vitro, necesita los factores $X$ y V. El factor $X$ o hemina es estable al calor, contiene protoporfirinas necesarias para el funcionamiento de citocromos en la cadena de transporte de electrones, catalasas y peroxidasas. Este factor es útil para distinguir entre las especies de Haemophilus, ya que $H$. parainfluenzae no requiere del factor $X$ para su crecimiento in vitro. El factor $V$ es una coenzima termolábil relacionada con los nucleótidos de adenina NAD y NADP. Sus 
requerimientos se pueden determinar por estos factores, utilizando discos o tiras comerciales en medios carentes de ellos, como tripticasa soya o Mueller-Hinton, y observando el patrón de crecimiento. De igual manera, se ha observado satelitismo alrededor de colonias de Staphylococcus aureus debido a su producción de factor $\mathrm{V}$, lo que permite identificar en forma presuntiva a $H$. influenzae. Sin embargo, no es una prueba definitiva, pues la estimulación del crecimiento también se presenta por especies de Pasteurella, Corynebacterum, Actinobacillus y algunos Haemophilus no NAD dependientes. Como pruebas adicionales de diferenciación para Haemophilus dependientes de NAD o hemina, se evalúa su patrón de hemólisis en agar sangre de caballo o de conejo al $3 \%$, la producción de catalasa y oxidasa, los patrones de fermentación de carbohidratos (glucosa, lactosa, sacarosa, xilosa y manosa), la producción de ortonitrofenil galactosidasa (ONPG), la producción de sulfuros de hidrógeno y el incremento de su crecimiento en atmósfera de $\mathrm{CO}_{2}$.

Sin embargo, la prueba de oro para la determinación del requerimiento del factor $X$ es la prueba de la sintesis de porfirinas. Se basa en la evaluación de la presencia de porfobilinógeno sintetasa y la consecuente transformación del ácido delta-aminolevulínico (d-ALA) en porfobilinógeno, lo cual se detecta por cambios de color en el medio, utilizando los reactivos de
Kovac o de Erhlich modificado, o por la producción de fluorescencia bajo luz ultravioleta (19).

Para la biotipificación, se utiliza un esquema elaborado por Kilian, basado en la utilización del indol, la urea y la ornitina, por medio de la actividad de enzimas específicas como la ureasa y la ornitina descarboxilasa. Adicionalmente, estas pruebas tienen utilidad epidemiológica, dado que el biotipo de un aislamiento individual, usualmente está relacionado con su fuente (20). Estas pruebas se utilizan para subdividir las especies en ocho biotipos diferentes (I-VIII).

Para la serotipificación (serotipos a-f), se utilizan métodos de aglutinación en placa; se realiza la reacción de Quellung, coaglutinación, inmunofluorescencia o contrainmunoelectroforesis. Las pruebas de aglutinación en látex y coaglutinación se basan en la detección del polisacárido capsular y son de mayor utilidad en muestras de líquido cefalorraquídeo y, con menor sensibilidad, en suero y orina (18).

Para evaluar la sensibilidad antimicrobiana, se estudia la producción de $\beta$-lactamasa a través de mediciones de acidometría, yodometria o por cefalosporinas cromogénicas (cefinasa). La detección de la enzima cloranfenicol-acetil transferasa (CAT), la sensibilidad a otros antimicrobianos por la técnica de difusión de disco en agar HTM (Kirby-Bauer) y, finalmente, la determinación de las concentraciones inhibitorias

Cuadro1. Identificación de Haemophilus influenzae por el laboratorio.

Crecimiento e identificación de Haemophilus $\mathrm{sp}$. Siembras en agar chocolate

Coloración de Gram-tinción de naranja de acridina

Prueba de porfirinas

Utilización de factores $\mathrm{V}$ y $X$

\section{Biotipificación de Haemophilus influenzae \\ Producción de indol \\ Hidrólisis de la úrea \\ Descarboxilación de la ornitina}

Pruebas de sensibilidad antimicrobiana

Producción de $\beta$-lactamasa

Detección de la cloranfenicol-acetiltransferasa (CAT)

Técnica de difusión de disco en agar HTM (Kirby-Bauer)

Determinación de concentración inhibitoria mínima (CIM)
Diferenciación de Haemophilus dependientes de NAD o hemina

Hemólisis en agar sangre de caballo o conejo al $3 \%$

Pruebas de catalasa y oxidasa

Fermentación de carbohidratos

Prueba de ONPG

Producción de $\mathrm{H}_{2} \mathrm{~S}$

Dependencia de $\mathrm{CO}_{2}$ (estimulación del crecimiento)

Serotipificación de Haemophilus influenzae

Aglutinación

Reacción de Quellung

Coaglutinación

Inmunofluorescencia

Contrainmunoelectroforesis 
mínimas (CIM) por microdilución en caldo o en agar o por la prueba de epsilon (E-test), confirman la categoria de la resistencia (19) (cuadro 1).

Varias estructuras de la superficie del microorganismo son fundamentales en los procesos de patogenicidad. La cápsula de polisacáridos que recubre a $H$. influenzae tipo b consta de repeticiones de polímeros de ribosilribitolfosfato (PRP) (21). Este hecho es de gran importancia, debido a que casi el $95 \%$ de las infecciones invasoras (meningitis, bacteremia) son causadas por el tipo b (22-24). Los otros serotipos capsulares están compuestos principalmente por hexosas y sólo ocasionalmente causan enfermedad invasora. Las cepas no capsuladas causan, de manera frecuente, infecciones del tracto respiratorio y estructuras adyacentes, pero casi nunca llevan a infecciones sistémicas. Las endotoxinas (lipooligosacárido) y algunas proteínas como adhesinas, IgA proteasas, hemosina y otras que forman filamentos (fimbrias o pili), constituyen factores importantes en la adhesión, patogenicidad y viabilidad del microorganismo $(25,26)$. De igual manera, las proteínas de membrana externa (OMP) cumplen funciones que aún no han sido bien determinadas del todo, pero que son fundamentales en estos procesos (27).

\section{Patogenia}

Con base en el biotipo y en el serotipo, se han determinado diferentes manifestaciones clínicas y patológicas de la infección por $H$. influenzae. El biotipo I se aisla con mayor frecuencia en los pacientes con meningitis, siendo $\mathrm{H}$. influenzae tipo b parte de este biotipo. Se ha encontrado usualmente mayor resistencia bacteriana en los biotipos I y II. En las vías urinarias se aislan generalmente los biotipos II, III y IV. EI biotipo IV es más común en infecciones neonatales y maternas (28).

Las infecciones asintomáticas y de las mucosas son las más comunes, ocasionadas, en su mayoría, por cepas no capsuladas que se encuentran en las vías respiratorias superiores en 50 a $80 \%$ de los portadores jóvenes y niños en edad preescolar. Sus principales manifestaciones se producen por extensión desde el tracto respiratorio, facilitadas por alteraciones en el hospedero debido a la presencia de reflujo en la trompa de Eustaquio, cuerpos extraños, alteraciones del epitelio en fumadores, antecedentes de infecciones virales o alteraciones inmunológicas puntuales, como las exacerbaciones de bronquitis crónica, otitis media, sinusitis y conjuntivitis, en tanto que la bacteremia es rara. Otros serotipos como el a, c y f se encuentran hasta en un $2 \%$ de los portadores y muy raramente se asocian con patologías (28).

Las infecciones invasoras se caracterizan por la diseminación hematógena del microorganismo y son ocasionadas, por lo general, por cepas capsuladas, principalmente tipo b, que se encuentran en 3 a $5 \%$ de los portadores y generalmente causan meningitis (hasta en $50 \%$ de los casos de enfermedad invasora) $(10,11,29)$, epiglotitis, neumonia, empiema, artritis séptica, celulitis, osteomielitis, pericarditis y bacteremia. De manera menos usual, causan glositis, tendosinovitis, peritonitis, endocarditis y ventriculitis. Es fundamental resaltar que esta clasificación no es excluyente y que se han reconocido cepas de serotipo b causantes de otitis media o sinusitis (30). Algunas cepas no capsuladas son causa poco común de sepsis neonatal (31) y hasta de un $50 \%$ de los casos de meningitis por $\mathrm{H}$. influenzae en edades mayores, especialmente en inmunosuprimidos o personas con defectos anatómicos, trauma encefálico o antecedentes de procedimientos neuroquirúrgicos. Algunas cepas no tipificables son causa común de infecciones invasoras del tracto respiratorio inferior en niños con malas condiciones socioeconómicas (32) y también de bacteremia en adultos (33).

\section{Epidemiología}

Los humanos son los únicos reservorios de $H$. influenzae. La bacteria se encuentra comúnmente en la faringe $y$, en menor grado, coloniza las mucosas de la conjuntiva y del tracto genital. La transmisión de persona a persona se produce por vía aérea o por contacto directo con secreciones respiratorias contaminadas; existe alguna evidencia de la transmisión por fómites (34). Algunos estudios han encontrado que hasta $80 \%$ de la población es portadora de $H$. influenzae, especialmente niños sanos que asisten a guarderías, la mayoría de 
ellos asintomáticos y portadores de cepas no capsuladas, las que, generalmente, cumplen varios ciclos de transmisión antes de generar la enfermedad en un hospedero susceptible, por lo que es difícil determinar con exactitud los periodos de incubación y el patrón de enfermedad durante endemias (35). La enfermedad invasora por $\mathrm{H}$. influenzae tipo b ocurre de manera endémica y entre 85 y $95 \%$ de los casos se presentan en niños menores de 5 años (36-38).

Los estudios de vigilancia epidemiológica llevados a cabo por el CDC de Atlanta, a través del National Haemophilus influenzae (Hi) Surveillance Program, estimaron la incidencia de la enfermedad invasora por $\mathrm{H}$. influenzae tipo b en los Estados Unidos en menores de 4 años en 1,8/100.000 en 1994 y 1,6/100.000 en 1995, es decir, aproximadamente 8.000 casos por año (39). Al comparar las incidencias anteriores a la introducción de la vacunación en 1985, que arrojaban datos entre 12.000 y 25.000 casos anuales, se evidencia una reducción muy importante $(40,41)$. En 1996 y 1997 , se informaron únicamente 144 casos confirmados de enfermedad invasora por $\mathrm{H}$. influenzae tipo b (42). En diversos estudios se ha observado un patrón de enfermedad estacional con un pico entre septiembre y diciembre y otro en marzo y mayo. La razón de estos picos se desconoce, pero se plantea la relación con los nacimientos y el ingreso al colegio de hermanos mayores, quienes introducen el microorganismo en el hogar (43).

En Colombia, las infecciones invasoras del tracto respiratorio inferior y la meningitis constituyen las principales causas de muerte y de hospitalización en menores de 5 años y se estima que $H$. influenzae puede ser responsable de $39 \%$ de esas muertes y hasta de $30 \%$ de los casos incidentes (44). Se ha calculado aproximadamente un número de 8.692 casos anuales de enfermedad del tracto respiratorio inferior o meningitis en menores de 5 años, de los cuales mueren $4.121(45)$.

Desde 1994, el Grupo de Microbiología del Laboratorio Nacional de Referencia del Instituto Nacional de Salud, en colaboración con 17 Laboratorios de Salud Pública de diferentes departamentos, estableció el programa de vigilancia de meningitis bacteriana aguda con el fin de mejorar la calidad del diagnóstico y conocer la frecuencia de aislamiento de los principales agentes etiológicos, sus serotipos y el patrón de susceptibilidad. En 1995, se lograron recolectar 130 aislamientos de 11 ciudades o departamentos, de los cuales los de $\mathrm{H}$. influenzae representaban el $45 \%$, seguidos de Neisseria meningitidis (27\%). En menores de 5 años fue el más frecuente $(60 \%)$, seguido de Streptococcus pneumoniae (20\%) y Neisseria meningitidis $(17 \%)(46,47)$.

Del total de aislamientos de LCR obtenidos en 1996 ( $n=248)$, provenientes de 13 de los 17 Laboratorios de Salud Pública, 110 (44,4\%) fueron $H$. influenzae serotipo $b$, de los cuales, $88,2 \%$ fueron recuperados en niños menores de 5 años. Los Laboratorios de Salud Pública Departamentales informaron haber procesado 4.548 muestras de LCR, de las cuales $329(7,2 \%)$ tuvieron un aislamiento y, de éstos, $100(30,4 \%)$ correspondian a H. influenzae (48).

En 1997, el Sistema de Vigilancia Epidemiológica del Ministerio de Salud (SIVIGILA), denominado entonces Sistema Alerta Acción, informó 334 casos de meningitis por $H$. influenzae. Se estimó la tasa de incidencia para ese año en $32,6 / 100.000$ niños menores de 5 años (49). De igual manera, en 1998 se informaron 306 casos, principalmente en las regiones de la Costa Atlántica (51 casos) y la región Centro Oriente (100 casos). Antioquia, Bogotá, Valle y Cesar fueron las regiones de mayor notificación con $72(23,5 \%), 59(19,2 \%), 39$ $(21,7 \%)$ y 21 casos $(6,8 \%)$, respectivamente $(50)$. En 1999, el SIVIGILA informó 159 casos, provenientes de: Antioquia, 33 casos $(20,7 \%)$; Santander, 30 casos (18,8\%); Bogotá, 17 casos $(10,6 \%)$ y Cartagena, 12 casos $(7,5 \%)(51)$. Finalmente, en el 2000 se informaron 119 casos de meningitis por este agente; fueron Antioquia, Cundinamarca, Sucre y Bogotá las regiones de mayor notificación con $29(24,3 \%), 18(15,1 \%)$, $10(8,4 \%)$ y 9 casos $(7,5 \%)$, respectivamente $(52)$. Hasta el 13 de enero de 2001 (segunda semana epidemiológica), únicamente Meta y Boyacá han informado dos casos de meningitis por $\mathrm{H}$. influenzae (53).

En el Primer Congreso Mundial de Infectología Pediátrica realizado en México en 1996, se 
evaluaron los informes locales de etiología de meningitis en menores de 5 años y se encontró que en Cartagena la tasa de incidencia fue de $41 / 100.000$ entre 1991 y 1993; en Bogotá, de 48/100.000 entre 1988 y 1996, y según los datos del Ministerio de Salud, la tasa en Colombia fue de 46/100.000 en 1995 (54).

Desde agosto de 1999, el Instituto Nacional de Salud, con la participación del Ministerio de Salud, la OPS y las Secretarías de Salud y hospitales de cuatro ciudades del país, está desarrollando un estudio multicéntrico de casos y controles para evaluar la efectividad de la vacuna anti- $H$. influenzae serotipo $b$ en neumonías bacterianas. Hasta el 11 de junio de 2000 , se habian identificado 237 casos y 432 controles, en los que el análisis preliminar indica que los factores de riesgo asociados con la ocurrencia de neumonía bacteriana son la presencia de una enfermedad de base y el antecedente de hospitalización previa por enfermedad respiratoria, el hacinamiento en la vivienda, la asistencia a hogares comunitarios, el vivir en inquilinatos o tugurios y peso al nacer menor de $2.500 \mathrm{~g}$ (55).

La relevancia de este microorganismo en la salud pública de nuestro país y del mundo es evidente y subraya la necesidad de generar programas de vigilancia epidemiológica para la evaluación de las enfermedades producidas por este agente y el impacto de las medidas de prevención y control que se implementen.

\section{Inmunidad}

La enfermedad por $\mathrm{H}$. influenzae requiere de ciertas condiciones para su generación. El hospedero debe pasar por una serie de etapas. Inicialmente, debe estar expuesto al microorganismo y presentar la colonización de las membranas mucosas del tracto respiratorio superior. Como se mencionó anteriormente, hay un porcentaje importante de portadores asintomáticos. Se ha planteado que el tamaño del inóculo y una infección viral concomitante pueden ser factores que predisponen a esta enfermedad invasora (56). Aparentemente, los microorganismos ingresan al torrente sanguíneo al destruir las uniones estrechas entre las células de la mucosa respiratoria. La dinámica entre la proliferación bacteriana, los anticuerpos, el complemento y el sistema retículoendotelial determinan la severidad de la bacteremia $(57,58)$. A medida que progresa la infección y aumenta la bacteremia, se presentan siembras metastásicas en las membranas serosas (meninges, pleura, pericardio), pulmón o líquido sinovial (59).

Se ha estudiado cuidadosamente la susceptibilidad de adquirir el microorganismo y se ha descrito que la sangre de niños entre 3 meses y 3 años de edad carece de actividad bactericida contra el serotipo b, mientras que la mayoría de los neonatos, niños mayores y adultos la presentan (60). Alexander y colaboradores propusieron que el polisacárido capsular de polímeros de ribitol (PRP) tiene actividad antifagocítica intrínseca y que su fagocitosis debía ser promovida por la opsonización con anticuerpos específicos. Establecieron, entonces, que el mecanismo de anticuerpos contra PRP es un determinante mayor en la generación de la inmunidad protectora $(61,62)$. Estos anticuerpos séricos activan la propiedad bactericida del complemento, la opsonización in vitro y median la inmunidad protectora contra la infección invasora en humanos (63).

En el momento de la infección, los niveles de anticuerpos contra PRP son muy bajos o están ausentes. En la convalecencia permanecen bajos, especialmente en los menores de 15 meses. Esto se debe a la demora natural en la generación de la respuesta inmune ante polisacáridos y otros antígenos no dependientes de células T (64). La concentración sérica mínima de anticuerpos contra PRP asociado con la protección contra $H$. influenzae tipo $\mathrm{b}$, se ha calculado en un rango entre 0,04 y $1,00 \mathrm{mg} / \mathrm{ml}$ (65). Sin embargo, estos valores deben ser analizados críticamente, ya que existen variaciones importantes en los diferentes tipos de anticuerpos contra PRP y la afinidad por ellos.

Desde el punto de vista genético, se ha encontrado relación entre los fenotipos del grupo sanguíneo y el antígeno leucocitario humano (HLA) en pacientes susceptibles a la enfermedad invasora. Se ha determinado un fenotipo de baja respuesta, asociado con la ausencia del halotipo $\mathrm{G} 2 \mathrm{~m}(\mathrm{n})$. Es interesante anotar que éste se presenta en las 
poblaciones negra e hispana, las cuales presentan tasas de ataque mayores que la población blanca (66).

El papel de los factores de inmunidad local en las mucosas es poco comprendido. Se plantea, de manera especulativa, la posibilidad de anticuerpos secretores que podrian alterar la adhesión del microorganismo a las células. Por el contrario, la evidencia parece mostrar que los anticuerpos IgA pueden aumentar la susceptibilidad al bloquear la actividad de otros anticuerpos (67).

\section{Factores de riesgo}

El riesgo de desarrollar enfermedad por $H$. influenzae está determinado por factores tanto del microorganismo como del hospedero y del medio ambiente. Los factores del microorganismo son la infectividad, la capacidad de adhesión a las células del tracto respiratorio y la virulencia, como ya se mencionó.

Entre los factores del hospedero, podemos encontrar que usualmente el riesgo es mayor en las edades de 6 a 12 meses. La enfermedad invasora es poco común en menores de 6 meses debido, presumiblemente, a la reducida exposición, a los factores protectores maternos transplacentarios o a la lactancia. Cada tipo de enfermedad invasora tiene patrones de edad determinada; la edad en la que más comúnmente se presenta la meningitis es entre los 6 y los 9 meses y declina marcadamente después de los dos años $(68,69)$. Las celulitis son más comunes durante el primer año de vida, mientras que las epiglotitis lo son después del segundo año de vida (70).

Aunque la mayoría de los estudios indica una similitud entre los diferentes sexos, algunos estudios indican una posible incidencia de 1,2 a 1,5 veces mayor en niños que en niñas (71).

La población negra se ve afectada por enfermedad invasora y meningitis causada por $\mathrm{H}$. influenzae tipo b entre 2 y 4 veces más que la blanca $(72,73)$. Estas diferencias se plantean en torno a factores genéticos, como se mencionaba anteriormente. Los niños con enfermedades subyacentes como anemia de células falciformes, inmunodeficiencias primarias o adquiridas del complemento, neoplasias o esplenectomía, tienen mayor riesgo de presentar enfermedad invasora (74-76). Aún está en duda, aunque existe alguna evidencia experimental, que las infecciones previas 0 concomitantes con agentes virales puedan aumentar la susceptibilidad a la infección por $\mathrm{H}$. influenzae, debido a las alteraciones que ocasionan en el epitelio respiratorio, las cuales pueden favorecer los mecanismos de adhesión y penetración de la bacteria (62).

Se ha planteado como factor protector la lactancia materna en niños menores de 6 meses, presumiblemente por el paso de factores nutricionales maternos; en las madres lactantes se han identificado anticuerpos contra la cápsula polisacarídica de $H$. influenzae tipo $b$, que persisten entre uno y seis meses después del inicio de la lactancia. Inclusive en madres inmunizadas durante el embarazo, se encuentran títulos de anticuerpos hasta 20 veces mayores contra la cápsula del microorganismo $(77,78)$.

Con respecto al medio ambiente, se consideran factores de riesgo el hecho de asistir a guarderías y factores sociodemográficos como el bajo estrato socioeconómico, el bajo nivel de educación de los padres, la sobrepoblación en la vivienda, los fumadores en la familia y el tener hermanos mayores en centros educativos (79-81).

\section{Diagnóstico}

Al igual que la mayoria de las entidades patógenas, la historia clínica y el examen físico son pilares de un diagnóstico adecuado. El criterio primario, sin embargo, es el aislamiento y la confirmación microbiológica del microorganismo. Los hemocultivos, los cultivos de LCR y de otros fluidos normalmente estériles (sinovia, líquido pleural, pericárdico) son mandatorios en circunstancias adecuadas, incluso a pesar de haberse iniciado el manejo antimicrobiano. La tinción de Gram es una coloración rápida y económica y puede ser útil en algunos especímenes, especialmente de líquido cefalorraquídeo, según un estudio realizado por Estrada et al. (82), el cual arrojó una sensibilidad del $100 \%$ y una especificidad del $96,4 \%$. Está descrito que la coloración de Gram detecta alrededor del $85 \%$ de $H$. influenzae en LCR y la sensibilidad depende específicamente de la 
centrifugación previa y del número de microorganismos existentes, esto es, si se realiza en laboratorios de referencia especializados y por personal altamente capacitado y con experiencia. Por ello, no debe considerarse tan sensible ni tan específica, en general. La tinción fluorescente con naranja de acridina y la inmunofluorescencia, aunque sean utilizadas de manera poco frecuente, son de utilidad en algunos casos, especialmente con muestras escasas y con mínima concentración bacteriana (83). La reacción de Quellung es otro método utilizado para su identificación; consiste en la demostración mediante microscopía de la cápsula, secundaria a la interacción con anticuerpos específicos contra antígenos capsulares. Como se mencionó anteriormente, los requerimientos para el cultivo de $\mathrm{H}$. influenzae son exigentes y las muestras deben ser procesadas inmediatamente en los medios suplementados con los factores $\vee$ y $X$.

Otras técnicas disponibles y de gran utilidad incluyen la detección de antígenos capsulares por técnicas de aglutinación de látex, coagiutinación e inmunoelectroforesis de contracorriente (CIE), en ese orden de sensibilidad. En diversos estudios, la aglutinación de látex ha demostrado sensibilidades muy elevadas (casi del 100\%), independientemente del fluido corporal estudiado, mientras que la coaglutinación presenta una sensibilidad de $86 \%$ en muestras de LCR, pero disminuye hasta $27 \%$ en otras como orina y suero. De la misma manera, la CIE presenta una sensibilidad de $91 \%$ en LCR, pero disminuye a $40 \%$ en orina y suero (84-86). Sin embargo, se pueden presentar falsos positivos en casos de reacciones cruzadas con otros organismos, especialmente Streptococcus pneumoniae, con el factor reumatoideo o en sujetos inmunizados recientemente con vacunas conjugadas contra $\mathrm{H}$. influenzae tipo b. También se presentan falsos negativos por exceso de antígenos de PRP (efecto prozona) y deficiencias en el proceso de centrifugación de las muestras (87).

\section{Enfermedades específicas}

En datos obtenidos por Peltola (88), de 3.931 pacientes incluidos en 21 estudios desarrollados en diferentes regiones del mundo entre las décadas de 1970 y 1990, se encontró que más del $90 \%$ de las enfermedades invasoras por $\mathrm{H}$. influenzae tipo b se manifestaban como seis entidades clásicas: meningitis $(52 \%)$, neumonía $(12 \%)$, epiglotitis $(10 \%)$, septicemia $(8 \%)$, celulitis $(5 \%)$ y enfermedades osteoarticulares $(4 \%)$, siendo la artritis séptica más común que la osteomielitis. Otras manifestaciones clínicas comprendian el $3 \%$ del número total y las enfermedades multifocales, el $6 \%$ restante.

Meningitis: es la complicación más severa de la infección invasora por $\mathrm{H}$. influenzae, siendo el serotipo b invariablemente el responsable. Usualmente hay un cuadro prodrómico de infección de vías respiratorias superiores que dura unos pocos días e, incluso, es común encontrar casos de otitis media, seguido por un período de franco deterioro. En algunos casos, la evolución de la enfermedad es fulminante y ocasiona la muerte en pocas horas, usuaimente en menores de un año. Al igual que la mayoría de las meningitis, los síntomas neurológicos y la fiebre son las principales manifestaciones clínicas, aunque los pacientes menores suelen presentar menos síntomas específicos y usualmente la rigidez nucal está ausente. Otras manifestaciones más severas como las convuisiones o el coma se presentan con la evolución de la enfermedad. Por lo general, la sintomatología es indistinguible de otras meningitis de etiologia bacteriana. La infección en neonatos es rara, pero puede ser similar a la ocasionada por Streptococcus del grupo B.

La complicación más común es la efusión subdural, debido a la poca edad de los pacientes (menores de 5 años, usualmente). En niños menores, la falta de respuesta al tratamiento antimicrobiano, signos de hipertensión endocraneana (fontanela abombada, papiledema), los signos neurológicos focales (indicativos del compromiso de pares craneanos) y los cambios en el estado mental deben aumentar la sospecha clínica. A pesar del diagnóstico y tratamiento adecuados, alrededor del $5 \%$ de los pacientes fallece (36). Las secuelas neurológicas se presentan hasta en un $30 \%$ de los sobrevivientes e incluyen retardo mental, pérdida de la audición (bilateral hasta un 18\%), alteraciones del crecimiento y aprendizaje, trastornos motores y síndromes convulsivos (89-91). 
Neumonia: la frecuencia de neumonías primarias por $H$. influenzae tipo $b$ en niños en los países desarrollados se desconoce y es difícil de estimar, pero se considera menor a $2 \%$ de todas las neumonías en niños (92). En los países subdesarrollados, sin embargo, hasta una tercera parte de las infecciones respiratorias bajas son causadas por cepas de $\mathrm{H}$. influenzae no tipificable y son una importante causa de morbimortalidad $(93,94)$. Sin embargo, su frecuencia parece haber disminuido comparada con la de décadas pasadas, probablemente debido al uso más racional y de mejores antimicrobianos. La sintomatología de las neumonías causadas por $H$. influenzae tipo b es similar a la causada por otras etiologías, aunque su inicio es más insidioso y se caracteriza por aparecer, hasta en un $43 \%$, junto con otro foco de infección, ya sea del tracto respiratorio superior -otits, epiglotitis- o incluso meningitis. La complicación más importante, aunque rara, es la pericarditis, caracterizada por disnea severa, taquicardia y evidencia de colapso cardiovascular. De igual manera, se pueden presentar bacteremia y empiema. Usualmente, por radiología se observan, en orden de frecuencia, patrones segmentarios, lobares, bronconeumónicos e interstiticiales. La efusión pleural se presenta.en más de la mitad de los pacientes, cuyo cultivo es positivo hasta en un $75 \%$. Las neumonías causadas por cepas no tipificables son también difícilmente distinguibles de las causadas por otros agentes patógenos, especialmente en pacientes con enfermedades pulmonares subyacentes tales como bronquitis crónica, infecciones virales previas, fibrosis quística e hipogammaglobulinemia (95).

Epiglotitis: es una enfermedad letal con un inicio característicamente fulminante. Los pacientes, usualmente niños entre dos y tres años de edad, presentan un cuadro de infección respiratoria superior, disnea y fiebre, que rápidamente progresa a disfagia y acumulación de secreciones orales. El niño adopta una posición característica, sentado y con hiperextensión del cuello (96). El deterioro se presenta en ausencia de manejo adecuado y lleva a la muerte en pocas horas.

Otros cuadros pueden presentarse de forma subaguda, con un cuadro prodrómico de horas a días antes del inicio de los síntomas agudos. El examen laríngeo debe realizarse en un lugar adecuado donde se pueda hacer una intubación de urgencia debido al riesgo inminente de espasmo laríngeo.

Celulitis: se observa predominantemente en niños pequeños y en menores de dos años. Se presenta usualmente en la cara (especialmente en región periorbital o geniana) o el cuello. Se manifiesta con edema, eritema, dolor que progresa en pocas horas acompañado, en la mayoría de los casos, de un foco subyacente de infección o de bacteremia, por lo que es importante instaurar un manejo antimicrobiano rápidamente (95).

Artritis séptica: $H$. influenzae es la causa más común de artritis séptica en menores de dos años. Típicamente, involucra articulaciones mayores sin generar osteomielitis. Se presenta con dolor, edema y disminución de la movilidad. Los hemocultivos y cultivos de sinovia son usualmente positivos. También puede presentarse de manera más sutil, con cuadros febriles prolongados e irritabilidad, especialmente asociados con meningitis (hasta en un $30 \%$ ), caso en el cual es común encontrar cultivos negativos de líquido sinovial con antígenos positivos (58).

\section{Tratamiento}

Debido a las características de la infección invasora por $\mathrm{H}$. influenzae, es importante iniciar un manejo antimicrobiano adecuado que penetre la barrera hematoencefálica, asegure concentraciones elevadas en LCR y tenga una duración prolongada para esterilizar los focos primarios y posibles focos secundarios.

La resistencia a cloranfenicol, ampicilina, trimetroprim-sulfametoxasol y cefalosporinas de segunda generación, se ha convertido en un problema en muchas áreas del mundo. La resistencia se da, básicamente, por producción de $\beta$-lactamasa tipo TEM-1, mediada por plásmidos (97), aunque otros mecanismos se presentan en el 0,1\% de cepas resistentes (98).

Tradicionalmente, se utilizó la ampicilina a dosis de $200-300 \mathrm{mg} / \mathrm{kg} / \mathrm{di} a$, IV cada 6 horas, pero debido a que hasta $50 \%$ de las cepas de $H$. influenzae tipo $b$ aisladas en Estados Unidos son resistentes, 
su uso debe ir acompañado de otro agente cuando se utiliza como terapia empírica contra la enfermedad invasora hasta comprobar la producción o no de $\beta$-lactamasa. La duración del tratamiento depende del sitio de la infección y de la respuesta clínica al mismo, pero usualmente no es menor de 10 dias. El cloranfenicol tuvo excelentes resultados en las infecciones severas y fue tradicionalmente la droga de elección junto a la ampicilina; su dosificación es de 75 a 100 $\mathrm{mg} / \mathrm{kg} /$ día IV cada 6 horas y continúa siendo un antimicrobiano de segunda elección. Su resistencia se ha presentado en regiones aisladas del globo y ha llegado en algunos casos hasta 50\% (58). No hay que olvidar los efectos secundarios sobre la médula ósea, especialmente en neonatos o pacientes con alteraciones hepáticas, los cuales son reversibles y dependen de la dosis.

En Colombia, según un estudio con datos desde 1994 en el que se analizaron 88 aislamientos de $H$. influenzae causante de meningitis aguda, se encontró que $9,1 \%$ era resistente a trimetroprimsulfametoxasol, $3,4 \%$ a cloranfenicol y $2,3 \%$ eran betalactamasa positivos (99). En otro estudio realizado por el Grupo de Microbiología del Instituto Nacional de Salud, se evaluaron 264 aislamientos de LCR y hemocultivos, recibidos entre 1994 y 1997. Se estableció que $10 \%$ de los aislamientos de LCR y $28 \%$ de los de hemocultivo presentaban sensibilidad disminuida a la ampicilina, con resistencia franca en 6 y $18 \%$, respectivamente. Se determinó que el $6,5 \%$ de los aislamientos de LCR y el $22 \%$ de los de hemocultivos eran productores de $\beta$-lactamasa. Con respecto al cloranfenicol, $5,8 \%$ de aisiamientos en LCR y $15 \%$ de hemocultivos presentaban sensibilidad disminuida, mientras que 5,3 y $15,1 \%$, respectivamente, presentaron franca resistencia. En relación con el TMP-SMX, $12 \%$ de los aislamientos de LCR y $87 \%$ de los hemocultivos presentaron sensibilidad disminuida. Solo $1 \%$ de los aislamientos presentó sensibilidad intermedia a la cefuroxima y todos fueron sensibles a la ceftriaxona. En términos generales, los aislamientos de neumonía presentaron mayor resistencia que los de meningitis (100).

Actualmente, la recomendación es el uso de cefalosporinas de tercera generación como terapia inicial en el manejo de la enfermedad invasora, especialmente meningitis, hasta que la susceptibilidad del microorganismo se determine. Se utilizan cefalosporinas que penetren adecuadamente en el LCR, como cefotaxima 200 $\mathrm{mg} / \mathrm{kg} / \mathrm{dia}$ cada 6 horas o ceftriaxona $75-100 \mathrm{mg} / \mathrm{kg}$ una o dos veces al dia (101). Sin embargo, aunque in vitro sean más efectivas, in vivo tardan más en esterilizar el LCR y no mejoran las tasas de fatalidad $(102,103)$. La cefuroxima no se utiliza en el tratamiento de meningitis por $\mathrm{H}$. influenzae tipo b, ya que tarda hasta el doble de tiempo que los otros agentes en esterilizar el LCR (104). Independientemente del manejo, el tratamiento debe prolongarse hasta que el paciente esté afebril y sin signos clínicos o de laboratorio durante 3 a 5 dias. La duración usual de la terapia es de 7 a 10 días. Los pacientes con endoftalmitis, endocarditis, pericarditis u osteomielitis requieren hasta de 3 a 6 semanas de manejo antimicrobiano (58).

Varios estudios han mostrado que, en algunas meningitis, especialmente aquellas causadas por organismos encapsulados, el uso adjunto de dexametasona a dosis de $0,6 \mathrm{mg} / \mathrm{kg}$ cada 6 horas durante 4 días, desde antes de la primera dosis de antimicrobiano, modera la cascada de la inflamación y disminuye el riesgo de la pérdida de la audición (105).

El manejo antimicrobiano es sólo uno de los pilares del tratamiento y deben establecerse medidas adecuadas de soporte tanto hidroelectrolítico como ventilatorio y nutricional para estos pacientes, incluidas las precauciones de aislamiento respiratorio, incluso 24 horas después de haber iniciado el manejo antimicrobiano.

El uso de rifampicina a $20 \mathrm{mg} / \mathrm{kg} /$ día durante 4 días (dosis máxima, $600 \mathrm{mg}$ ) en niños y contactos, se utiliza como profilaxis ya que erradica hasta en $95 \% \mathrm{H}$. influenzae tipo b en los portadores, el cual no logra ser erradicado por el tratamiento sistémico. Algunos datos parecen demostrar que esta profilaxis reduce la incidencia de la enfermedad invasora secundaria. EI CDC de Atlanta para todos los contactos intradomiciliarios recomienda la profilaxis, excepto las mujeres embarazadas, sin importar la edad, si han estado en contacto con un niño menor de 4 años que no esté inmunizado o que se encuentre parcialmente inmunizado, así 
como para todos los miembros domiciliarios de un niño menor de 12 meses, incluso si las primeras dosis de la vacuna se han aplicado, y para todos los miembros domiciliarios de un niño inmunocomprometido sin importar su estado vacunal contra $H$. influenzae. Los niños de guardería o preescolar, sin importar la edad, si se han presentado dos o más casos de enfermedad invasora en los 60 días anteriores también deben recibir profilaxis. El caso índice también debe recibir quimioprofilaxis si fue tratado con antimicrobianos diferentes a ceftriaxona 0 cefotaxime, la cual usualmente se administra antes de su salida del hospital (106) (cuadro 2).

\section{Vacunas contra Haemophilus Influenzae tipo b}

Las primeras vacunas disponibles para la prevención de $H$. influenzae tipo b fueron desarrolladas a partir de la purificación de polisacáridos PRP y autorizadas en Estados Unidos en abril de 1985 (b-CAPSA ${ }^{\circledR}$, Hib-VAX®, Hib-IMUNE $(\mathbb{R})$; éstas ya no se encuentran en el mercado (107). La respuesta inmunogénica ante estas vacunas era directamente proporcional a la edad, siendo los niños menores seroconvertidores erráticos $\mathrm{y}$, frecuentemente, con bajos niveles séricos (108). No se establecieron efectos secundarios mayores con este tipo de vacunas, excepto algunos informes aislados de casos de enfermedad por $\mathrm{H}$. influenzae tipo b una semana después de la vacunación (109). Posteriormente, se han desarrollado múltiples vacunas basadas en conjugados proteicos de PRP, los cuales utilizan los principios de presentación antigénica mediada por haptenos definida por Ladsteiner en 1924 (110), es decir, una proteína inmunogénica transportadora que es reconocida por células $T$ y macrófagos, la cual estimula la inmunidad dependiente de estas células. La proteína es covalentemente conjugada a los polisacáridos de PRP, que, de por sí, confieren respuesta inmunológica (111). Las diferentes marcas comerciales emplean el mismo hapteno (PRP), pero difieren en el tamaño de los polisacáridos, el transportador proteico y el tipo de conjugación, así como en su respuesta inmunogénica (112).

En 1987, se lanzó al mercado una nueva vacuna, esta vez conjugada con toxoide diftérico (vacuna PRP-D, ProHIBiT (B) (113). Posteriormente, se desarrollaron vacunas conjugadas de oligosacáridos de $\mathrm{H}$. influenzae tipo b ( $\mathrm{HbOC})$, en diciembre de 1988 y 1989 (HibTITER®), constituidas por pequeños segmentos de oligosacáridos unidos a

Cuadro 2. Indicaciones para la profilaxis con rifampicina a los contactos y casos índices de enfermedad por Haemophilus influenzae tipo $b$ *

Quimioprofilaxis no recomendada

Ocupantes domiciliarios sin niños menores de 4 años, diferentes al caso indice.

Ocupantes domiciliarios cuando todos los contactos menores de 4-8 meses de edad han completado su esquema de vacunación contra $H$. influenzae.

Niños en guarderias y preescolar contactos de un caso indice, especialmente aquéllos mayores de 2 años de edad.

Mujeres en estado de embarazo

Quimioprofilaxis recomendada

Todos los contactos intradomiciliarios, excepto mujeres embarazadas, sin importar la edad, si han estado en contacto, con, por lo menos, un niño menor de 4 años que no esté inmunizado o que se encuentre parcialmente inmunizado.

Todos los miembros domiciliarios con un niño menor de 12 meses, incluso si las primeras dosis de la vacuna se han aplicado.

Todos los miembros domiciliarios de un niño inmunocomprometido sin importar su estado vacunal contra $H$. influenzae. Niños de guarderia o preescolar, sin importar la edad, si se han presentado 2 o más casos de enfermedad invasora en los 60 dias anteriores.

El caso indice también debe recibir quimioprofilaxis si fue tratado con antimicrobianos diferentes a ceftriaxona o cefotaxime, usualmente administrada antes de su salida del hospital.

\footnotetext{
* Modificado de: Haemophilus influenzae infections. En: Commitee of Infectious Diseases, American Academy of Pediatrics. Red Book 2000. 25th edition. Chicago, IL: American Academy of Pediatrics; 2000.
} 
una proteína transportadora $\mathrm{CRM}_{197}(114)$. Esta se asoció con la vacuna DTP y salió al mercado en marzo de 1993 (TETRAMUNE ${ }^{\circledR}$ ), ya que se evidenció una mayor respuesta antigénica en pacientes vacunados anteriormente con DPT. También se desarrollaron vacunas conjugadas fabricadas a partir de la unión del PRP con proteínas de membrana externa de Neisseria meningitidis serogrupo B, (PRP-OMP), y se utilizó timerozal, un derivado de etilmercurio, como preservativo y estabilizador. Su respuesta inmunológica era más favorable, siendo menos edad-dependiente, y con una sola dosis se

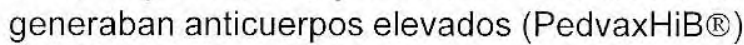
(115). Para esta época, se lanzó al mercado la PRP-T, una de las primeras vacunas desarrolladas en el Instituto Nacional de Salud de los Estados Unidos (ActHIB $\AA$, OmniHIB $®)$, la cual se basaba en la conjugación de los polímeros de polisacáridos con un transportador de toxoide tetánico.

Desde 1996, se han asociado otras vacunas dentro de la misma presentación, creando así vacunas trivalentes (TriHIBit $\AA$, Comvax $\AA$ ) y pentavalentes (Pentact-Hib®, POLIACEL $®$ ), con el objeto de disminuir el número de inyecciones necesarias para vacunar a los menores, manteniendo e incluso, incrementando su inmunogenicidad (cuadro 3).

Debido a la declinación de los niveles de anticuerpos que sobreviene con el tiempo, se recomienda una dosis de refuerzo entre los 12 y 15 meses de edad. Aún no es claro si una sola dosis de refuerzo es suficiente para generar inmunidad de por vida.

No hay contraindicaciones específicas con relación a las vacunas conjugadas contra $H$. influenzae tipo b. Las contraindicaciones generales aplicadas a todas las vacunas son las mismas; pueden ser administradas a individuos inmuno-comprometidos, aunque la inmunogenicidad en estos grupos puede ser menor (116).

El 14 de julio de 2000, en las reuniones entre la American Academy of Family Physicians, la

Cuadro 3. Diferentes vacunas desarrolladas contra Haemophilus influenzae, tipo b. +

\begin{tabular}{|c|c|c|c|c|}
\hline $\begin{array}{l}\text { Nombre } \\
\text { vacuna }\end{array}$ & $\begin{array}{l}\text { Nombre } \\
\text { comercial }(B)\end{array}$ & $\begin{array}{c}\text { Casa } \\
\text { farmaceútica }\end{array}$ & Fecha & Componentes \\
\hline PRP & $\begin{array}{l}\text { b-CAPSA } 1^{*} \\
\text { Hib-VAX * } \\
\text { Hib-IMUNE* }\end{array}$ & $\begin{array}{l}\text { Praxis } \\
\text { Connaught } \\
\text { Lederle }\end{array}$ & 1985 & Polisacáridos de PRP purificados \\
\hline PRP-D & Pro-HIBiT & Connaught & $1987-1989$ & Polisacáridos de PRP conjugados con toxoide diftérico \\
\hline $\mathrm{HbOC}$ & HibTITER & Lederle/Praxis & $1988-1990$ & Oligosacáridos de $\mathrm{H}$. influenzae + trasportador $\mathrm{CRM}_{197}$ \\
\hline HbOC-DTP & TETRAMUNE & Lederle/Praxis & 1993 & $\mathrm{Hb}$ OC asociada a DTP \\
\hline PRP-OMP & PedvaxHIB & Merck \& Co. & $1989-1990$ & $\begin{array}{l}\mathrm{PRP}+\text { proteinas de membrana externa de Neisseria } \\
\text { meningitidis, serogrupo } \mathrm{B} \text {. }\end{array}$ \\
\hline PRP-T & $\begin{array}{l}\text { ActHIB } \\
\text { OmniHiB }\end{array}$ & $\begin{array}{l}\text { Pasteur Merieux } \\
\text { Smith Kline B. }\end{array}$ & 1993 & $\begin{array}{l}\text { Conjugado de proteínas de PRP conjugadas con } \\
\text { toxoide tetánico }\end{array}$ \\
\hline DTaP-PRP-T & TriHIBit & $\begin{array}{l}\text { Connaught } \\
\text { Merieux }\end{array}$ & 1996 & $\begin{array}{l}\text { PRP-T conjugada con vacuna acelular de Pertussis y } \\
\text { toxoide tetánico }\end{array}$ \\
\hline PRP-OMP-HepB & Comvax & Merck \& Co. & 1996 & $\begin{array}{l}\text { PRP-OMP conjugada con vacuna de hepatitis } B \\
\text { recombinante }\end{array}$ \\
\hline DPT-IPV-PRP-T & Pentact - Hib & Aventis & 1996 & $\begin{array}{l}\text { Difteria + Pertussis, células completas + poliovirus } \\
\text { inactivado + liofilizado de PRP-T }\end{array}$ \\
\hline DTaP-IPV-PRP-T & POLIACEL & Aventis & 1997 & $\begin{array}{l}\text { Difteria + Pertussis acelular + poliovirus inactivado + } \\
\text { liofilizado de PRP-T }\end{array}$ \\
\hline
\end{tabular}

* No disponibles actualmente

+ Modificado de: Ward J, Zangwill K. Haemophilus influenzae vaccines. En: Plotkin SA, Orenstein WA, editores. Vaccines. Third Edition. Philadelphia: WB Saunders Company; 1999. p.196. 
American Academy of Pediatrics, el Advisory Committee on Immunization Practices y el U.S. Public Health Service y en respuesta a la preocupación por la exposición a mercurio, se determinó la eliminación del uso de timerozal como componente de las vacunas. Desde principios de julio de 2000, solamente vacunas contra $H$. influenzae tipo b libres de timerozal se producen en los Estados Unidos, aunque aún se continúan distribuyendo viales previamente fabricados(117).

El Advisory Committee on Immunization Practices (ACIP) recomienda con relación al esquema de inmunización infantil para el período 2000-2001, la vacunación con PRP-T, $\mathrm{HbOC}$ o HbOC-DTP contra $H$. influenzae tipo $b$, con dosis a los 2, 4 y 6 meses y con un refuerzo entre los 12 y 15 meses; para la vacuna PRP-OMP, dosis a los 2 y 4 meses, con refuerzo entre los 12 y 15 meses.

El futuro en este campo se centra en el desarrollo de nuevas vacunas polivalentes que contengan alternativas antigénicas promotoras de protección adicional contra infecciones por $\mathrm{H}$. influenzae tipo $b$ y, más importante aún, que generen inmunidad contra cepas no tipificables y, de igual manera, faciliten los esquemas de vacunación y disminuyan las molestias del paciente pediátrico.

\section{Impacto}

La introducción de la vacuna conjugada contra $H$. influenzae tipo b en países industrializados ha llevado a la desaparición casi total de las infecciones invasoras por este microorganismo (118). Según estudios del CDC de Atlanta, la incidencia de enfermedad invasora en menores de 4 años en Estados Unidos ha disminuido $98 \%$ desde el licenciamiento inicial de la vacuna en 1989 (119). A pesar de que el cubrimiento nacional en 1995 era alrededor del $90 \%$ en los niños de 19 a 35 meses, con tres o más dosis, y que algunas áreas metropolitanas tenían un cubrimiento un poco menor, la incidencia de la enfermedad en 1994 y 1995 fue $98 \%$ menor que en la era prevacunación (120). En los lugares de vigilancia activa, la incidencia ajustada para la raza disminuyó 99\% entre 1989 y 1995. La incidencia global de enfermedad invasora en menores de 5 meses pasó de $148 / 100.000$ hab en 1988 a 2,2/100.000 en 1995 , inclusive sin haber recibido el esquema completo debido a su corta edad (121). Estos resultados excedieron las expectativas al evaluar una sola serie primaria de vacunación lo que probablemente, se debe a la capacidad de la vacuna de reducir los portadores faríngeos, estableciendo, además, una inmunidad de rebaño que protege a los no vacunados, asociación también registrada en los países europeos (122).

En Latinoamérica, Chile y Uruguay fueron los primeros y, de hecho, los primeros países no industrializados (junto con Qatar en Asia) en utilizar la vacuna conjugada contra $H$. influenzae tipo $b$ (123). Sin embargo, en años recientes, se ha incluido la vacuna en los Programas Ampliados de Inmunizaciones (PAI) de Argentina, Costa Rica, Brasil, El Salvador, México, Colombia, Venezuela y Perú (124).

Chile fue el primer país en Latinoamérica en demostrar los beneficios de la vacuna contra $H$. influenzae tipo b. Se observó una disminución de $90 \%$ en la incidencia de la enfermedad invasora entre 1995 y 1998 (125). Sin embargo, Uruguay fue el primer país en consolidar un programa de vacunación a nivel nacional con una disminución en la incidencia de más de $58 \%$ entre $1992-93$ y 1995-96 (126-128).

En Costa Rica se utilizó la vacuna inicialmente en el sector privado y, posteriormente, se estableció como medida de rutina en la infancia, lo cual llevó, entre 1992 y 1994, a una disminución del $57 \%$ en las admisiones hospitalarias por enfermedad invasora al único hospital de tercer nivel de la región $(129,130)$.

Adicionalmente, en estudios realizados en América Latina, se han corroborado los informes anteriores de efectividad del uso de dosis fraccionadas (un medio y un tercio de la dosis total) de la vacuna conjugada con toxoide tetánico (PRP-T), que pueden estimular concentraciones de anticuerpos adecuadas $(>0,15 \mathrm{mg} / \mathrm{ml})$ en 91 a $100 \%$ de los niños inmunizados, una frecuencia similar al $93 \%$ de la seroconversión a niveles protectores adquirida con las dosis completas (108). Este factor se atribuye, entre otros, a los mecanismos de memoria inmunológica que permiten una rápida respuesta anamnésica ante la reexposición (131). De igual manera, se ha demostrado que hay un 
alto porcentaje de seroconversión con una sola dosis de la vacuna PRP-OMP, la cual puede ser una alternativa válida en poblaciones con altas frecuencias de enfermedad invasora en menores de seis meses y cuyos factores logísticos y socioeconómicos puedan dificultar el uso de otras vacunas o de esquemas completos (114).

En Colombia, entre 1994 y 1999, el Grupo de Microbiología del Instituto Nacional de Salud confirmó que el $43,3 \%$ de las meningitis bacterianas agudas eran causadas por $H$. influenzae y, basado en el cálculo de los casos esperados en menores de un año entre junio de 1998 y mayo de 1999, se evidenció una disminución del $40 \%$ en el número de casos de meningitis bacteriana aguda en menores de un año causada por este agente, teniendo en cuenta que desde mayo de 1998 se inició la vacunación contra $\mathrm{H}$. influenzae tipo $\mathrm{b}$ en este grupo de edad en el país (132).

Sin embargo, son múltiples los problemas a nivel nacional que han impedido coberturas vacunales mayores. Según el Grupo de Prevención y Control de Enfermedades del Programa Ampliado de Inmunizaciones 2000-2001, la cobertura del PAI ha ido en descenso desde 1997, lo cual se atribuye, en parte, a los procesos de descentralización que brindan autonomía a los alcaldes para manejar los fondos del programa de salud pública a través de las secretarías de salud municipales o distritales, y al hecho de que los sistemas de información se encuentran aún en proceso de adecuación, así como a la situación de orden público y los desplazamientos en diferentes regiones del país, lo cual ha generado inconsistencias en los denominadores de población. Para el 2000 , la cobertura vacunal contra $\mathrm{H}$. influenzae tipo b a nivel nacional fue sólo de 58,9\% (Ministerio de Salud, Grupo de Prevención y Control de Enfermedades, Programa Ampliado de Inmunizaciones 2000-2001. Coberturas de Vacunación, 2000). A nivel departamental y regional, sin embargo, se observan variaciones importantes en las coberturas debido a factores específicos y no del todo bien determinados. Es el caso de departamentos como Cundinamarca, que obtuvo una cobertura de $92 \%$; Bogotá, 72,5\%; Caquetá, 71,7\%; Casanare, 71,4\%;
Huila, 72,3\%; Nariño, 79,6\%, y Tolima, $76,1 \%$, comparados con otros como Amazonas, con coberturas sólo de 17,7\%; Caldas, 21,5\%; Cauca, 27,9\%; Guainía, 20,0\%, y Guaviare, 25,5\% (133). Estas diferencias tan marcadas en las coberturas de vacunación están relacionadas, en parte, con los factores anotados anteriormente y también, de manera directa, con las deficiencias en los procesos de transporte de muestras, de conservación de la cadena de frío y la carencia de programas regulares de vacunación en algunos sectores apartados del país, donde los únicos mecanismos de vacunación son las campañas ocasionales.

\section{Conclusiones}

No existe ninguna otra enfermedad no epidémica e inmunoprevenible en el mundo que se encuentre tan bien caracterizada y que afecte a grupos de población tan bien definidos, pero que a la vez sea ignorada por tanta gente y registre zonas donde no hay cubrimiento alguno, ya que menos del $2 \%$ de las enfermedades por $H$. influenzae son prevenidas a nivel mundial, debido a que alrededor del $80 \%$ de los 215 países y territorios que informan a la OMS no utilizan vacunas contra este agente dentro de sus programas ampliados de inmunización $(81,134)$.

El uso de las vacunas conjugadas contra $H$. influenzae ha marcado un hito en la prevención de una de las enfermedades prevalentes más importantes en el mundo y se ha constituido como una de las medidas más efectivas jamás realizadas en la prevención de enfermedades inmunoprevenibles en general.

Debe evaluarse la posibilidad, según las características demográficas y considerando costo, facilidades de administración y de almacenamiento y de acuerdo con las características propias de la enfermedad, de elegir vacunas que promuevan un alto porcentaje de generación de anticuerpos a concentraciones protectoras adecuadas con la primera o primeras dos dosis, aunque, idealmente, debe promoverse la administración del esquema completo de vacunación, tal como está establecido en las recomendaciones internacionales.

El alto costo ha sido un obstáculo importante, pero existen mecanismos que evitan sacrificar las 
coberturas, entre los que cabe mencionar la disminución en el número de dosis aplicadas, el uso de dosis fraccionadas de vacunas conjugadas que ofrezcan porcentajes de seroconversión elevados, la implementación de vacunas polivalentes que reduzcan los costos de aplicación e incrementen la inmunogenicidad y, más importante aún, racionalicen la adquisición de vacunas con base en el análisis de los recursos físicos y económicos disponibles.

En realidad, la verdadera intervención en la reducción de costos no ha sido evaluada, pues los costos de adquisición y aplicación de la vacuna son sólo un pequeño porcentaje de aquéllos generados directa e indirectamente por la enfermedad y su prevención secundaria y terciaria. En Colombia, Restrepo y colaboradores (135) realizaron en 1998 un análisis de los costos mínimos generados por la atención de un paciente con meningitis aguda, incluidas las actividades de trabajo de campo para prevenir la diseminación de la enfermedad, y concluyeron que estaba alrededor de US $\$ 1.800$, mientras que la atención de la hipoacusia profunda -una de sus secuelasse estimó en US \$16.000.

Debe fortalecerse y promulgarse el uso y la diseminación de esta vacuna, especialmente en los países subdesarrollados donde las cifras de incidencia de enfermedad invasora continúan siendo altas, a pesar de las dificultades que ello pueda conllevar. Igualmente, es importante continuar y expandir los programas de vigilancia epidemiológica que permitan verificar el impacto de la vacunación y de otras intervenciones sanitarias y las tendencias de este impacto a mediano y largo plazo.

En nuestro país, a pesar de las pobres coberturas en algunos sectores, se ha evidenciado, sin embargo, un impacto importante sobre la enfermedad invasora por $\mathrm{H}$. influenzae tipo $\mathrm{b}$.

En vista de la reducción en las coberturas vacunales se hace necesario programar jornadas de vacunación a nivel nacional, fortalecer el Plan de Intensificación del Programa Regional de Vacunación, adecuar los sistemas de información del Programa Ampliado de Inmunizaciones (PAISOFT 2.0) y establecer los mecanismos para agilizar la adquisición de vacunas y su adecuada distribución, incluido el fortalecimiento logístico, de apoyo educativo, soporte técnico y de los requerimientos físicos para mantener la cadena de frío y asegurar la adecuada disponibilidad y distribución de los biológicos. De igual manera, es indispensable fortalecer los programas de vigilancia por laboratorio de la etiología de meningitis bacteriana y enfermedad invasora, y asesorar en forma directa a los departamentos de mayor riesgo para IRA y meningitis en el uso racional de los recursos disponibles para salud pública de acuerdo con su situación epidemiológica (Ministerio de Salud-Instituto Nacional de Salud. Proceso de empalme. Convenio interadministrativo para desarrollar la Resolución 00228 de 2001. Programa IRA-Meningitis Bacteriana Aguda, abril 2001).

\section{Agradecimientos}

Por sus comentarios y sugerencias, el autor agradece a Clara Inés Agudelo, Elizabeth Castañeda, Enrique Gutiérrez y Miguel Antonio Guzmán.

\section{Referencias}

1. Ward J, Zangwill K. Haemophilus influenzae vaccines. En: Plotkin SA, Orenstein WA, editores. Vaccines. Third Edition. Philadelphia: W.B. Saunders Company; 1999. p. 183.

2. Pfeiffer R. Vorlaufige mit Heilungen über die Erreger der Influenzae. Dtsh Med Wochenschr 1892;18:28-34.

3. Winslow CE, Broadhurst J, Buchanan RE. The families and genera of the bacteria: final report of the Committee of the Society of American Bacteriologist on characterization and classification of bacterial types. $\mathrm{J}$ Bacteriol 1920;5:191-229.

4. Pittman M. Variation and type specificity in the bacterial species Haemophilus influenzae. J Exp Med 1931;53: 471-95.

5. Alexander HE, Heidelberger M, Leidy G. The protective or curative element in type b Haemophilus influenzae rabbit serum. Yale J Biol Med 1944;16:42540.

6. Alexander HE. Experimental basis for treatment of Haemophilus influenzae infections. Am J Dis Child 1943; 66:160-71.

7. Sánchez Planas L, Vinas M. Non-typable Haemophilus influenzae from a single hospital: epidemiological markers. Microbios 1998;93:55-68.

8. Bolduc GR, Bouchet V, Jiang RZ, Geisselsoder J. Variability of outer membrane protein $\mathrm{P} 1$ and its 
evaluation as a vaccine candidate against experimental otitis media due to nontypable Haemophilus influenzae: an unambiguos, multifaceted approach. Infect Immun 2000;68:4505-17

9. Karalus RJ, Murphy TF. Purification and characterization of an outer membrane protein P6, a vaccine antigen of nontypable Haemophilus influenzae. FEMS Immunol Med Microbiol 1999;26:159-66.

10. Hendrixson DR, St Geme JW $3^{\text {rd }}$. The Haemophilus influenzae Hap serine protease promotes adherence and microcolony formation, potentiated by a soluble host protein. Mol Cell 1998;2:841-50

11. Yano $\mathbf{H}$, Suetake $\mathbf{M}$, Kuga A, Irinoda K, Okamoto $\mathbf{R}$ Pulsed-field gel electrophoresis analysis of nasopharyngeal flora in children attending a day care center. $\mathrm{J}$ Clin Microbiol 2000;38:625-9.

12. Bernstein JM, Bronson PM, Wilson ME. Immunoglobulin $G$ subclass response to major outer membrane proteins of nontypable Haemophilus influenzae in children with acute otitis media. Otolaryngol Head Neck Surg 1997;116:363-71.

13. Hendolin PH, Paulin L, Ylikoski J. Clinically applicable multiplex PCR for four middle ear pathogens. J Clin Microbiol 2000;38:125-32.

14. Morton DJ, Whitby PW, Jin H, Ren Z, Stull TL. Effect of multiple mutations in the hemoglobin- and hemoglobinhaptoglobin binding proteins, $\mathrm{HgpA}, \mathrm{HgpB}$, and $\mathrm{HgpC}$ of Haemophilus influenzae type b. Infect Imm 1999; 67:2729-39.

15. Sánchez L, Lenzaroz S, Puig M, Loren JG, Nikaido $H$. Molecular basis of antimicrobial resistance in nontypable Haemophilus influenzae. Microbiología 1997;13: 309-14.

16. Sánchez L, Pan W, Vinas $M$, Nikaido $H$. The acrAB homolog of Haemophilus influenzae codes for a functional multidrug efflux pump. J Bacteriol 1997;179: 6855-7.

17. Ward, J, Zangwill, K. Haemophilus influenzae vaccines. En: Plotkin SA., Orenstein WA, editors. Vaccines. Third Edition. W.B. Philadelphia: Saunders Company; 1999. p. 185.

18. Moxon ER. Haemphilus influenzae. En: Mandell GL, Bennett JE, Dolin R, editors. Principles and practice of infectious diseases. Fourth edition. New York: Churchill Livingstone Inc.; 1995. p.2039.

19. Organización Panamericana de la Salud, Programa Especial para Vacunas e Inmunización (SVI), Sistema Regional de Vacunas (SIREVA), Instituto Nacional de Salud. Taller sobre la identificación bioquímica y serológica de Haemophilus influenzae y Streptococcus pneumoniae. Manual de Haemophilus influenzae. Bogotá, DC:OPS; 1998. p.1-58.

20. Kilian M. A taxonomic study of the genus Haemophilus with the proposal of a new species. J Gen Microbiol 1976;93:9-62.
21. Crisel RM, Bajer RS, Dorman DE. Capsular polymer of Haemophilus influenzae type $b$. Structural characterization of the capsular polymer of strain Eagan. J Biol Chem 1975;250:4926-30.

22. Todd JK, Bruhn FW. Severe Haemophilus influenzae infections: spectrum of disease. Am J Dis Child 1975; 129:607-11.

23. Dajani AS, Asmar BI, Thirumoorthi MC. Systemic Haemophilus influenzae disease: an overview. J Pediatr 1979;94:335-64.

24. Halla IJ, Dobson SRM, Crook DWM. Population-based study of non-typeable Haemophilus influenzae invasive disease in children and neonates. Lancet 1993;341:8514.

25. Van Ham SM, van Alphen L, Mooi FR. Fimbriamediated adherence and hemagglutination of Haemophilus influenzae. J Infect Dis 1992;165:S97S99

26. Torres N, Posada R. Haemophilus influenzae. En: Correa JA, Gómez JF, Posada R, editores Fundamentos de pediatria. Enfermedades infecciosas y respiratorias. Tomo II. Medellín: Corporación para Investigaciones Biológicas; 1994. p. 687-8.

27. Van Schilfgaarde $M$, van Ulsen P, Eijk P, Brand M. Characterization of adherence of nontypable Haemophilus influenzae to human epithelial cells. Infect Immun 2000:68:4658-65.

28. Mendelman PM, Smith AL. Haemophilus influenzae. En: Feigin $\mathrm{H}$, editor. Textbook of pediatric infectious diseases. Third Edition. Philadelphia: Saunders Company; 1992. p. 1118.

29. Granoff DM, Basden M. Haemophilus influenzae infections in Fresno County, California: a prospective study of the effects of age, race and contact with a case on incidence of disease. J Infect Dis 1980;140:406.

30. Harding Al, Anderson P, Howie VM. Haemophilus influenzae isolated from otitis media. En: Sell SH, Karzon DT, editors. Haemophilus influenzae. Nashville, TN: Vanderbilt University Press; 1973, p. 21-7.

31. Wallace RJ, Baker CJ, Quinones FJ. Non-typeable Haemophilus influenzae (biotype 4) as a neonatal, maternal and genital pathogen. Rev Infect Dis 1983;5: 123-36.

32. Shannan F, Gratten M, Germer S. Aetiology of pneumonia in children in Goroka hospital, Papua, New Guinea. Lancet 1984;2:537-41.

33. Spagnuolo RJ, Ellner JJ, Lerner PI. Haemophilus influenzae meningitis: the spectrum of disease in adults. Medicine 1982;61:74-85.

34. Murphy TV, Clements JF, Petroni M. Survival of Haemophilus influenzae type $b$ in respiratory secretions. Pediatr Infect Dis J 1989;8:148-51. 
35. Moxon ER. The carrier state: Haemophilus influenzae. J Antimicrob Chemother 1986:18(Suppl A):17-24.

36. Makela PH, Takala AK, Peltola H, Eskola $d$. Epidemiology of invasive Haemophilus influenzae type b disease. J Infect Dis 1992;165:S2-S6.

37. Shapiro ED, Ward JI. The epidemiology and prevention of disease caused by Haemophilus influenzae type b. Epidemiol Rev 1991;13:113-42.

38. Moxon ER, Deich RA, Connelly CJ. Cloning of chromosomal DNA from Haemophilus influenzae: its use for studying the expression of type $b$ capsule and virulence. J Clin Invest 1984;73:298-306.

39. Bisgard KM, Kao A, Leake J, Strebel PM,Perkins BA, Wharton M. Haemophilus influenzae invasive disease in the United States, 1994-1995: near disappearance of a vaccine-preventable childhood disease. Emerg Infect Dis 1998;4:1-14.

40. Cochi Si, Broome CV. Vaccine prevention of Haemophilus influenzae type b disease. Past, present and future. Pediatr Infect Dis J 1986;5:12-9.

41. Cochi SL, Broome CV, Hightower AW. Immunization of U.S. children with Haemophilus influenzae type $b$ polysaccharide vaccine: a cost effective model of strategy assessment. JAMA 1985;253:521-9.

42. Centers for Disease Control and Prevention. Haemophilus influenzae type b. Disponible en: URL: http://www.cdc.gov/nip/publications/pink/hib.pdf.

43. Broome CV, Schelch WF III. Recent developments in the epidemiology of bacterial meningitis. En: Sande MA, Smith A, Root RD, editors. Bacterial meningitis. Edinburgh: Churchill Livingstone; 1985, p.1-10.

44. Ministerio de Salud. Oficina de Epidemiología. Informe ejecutivo semanal. Semana epidemiológica $11 ; 1998$.

45. INS. Cobertura universal con la vacuna conjugada de Haemophilus influenzae tipo b en Colombia. Inf Quinc Epidemiol Nac 1998;3:105-6.

46. De la Hoz F, Velandia MP. Epidemiologia de la infección por meningitis meningocóccica en Colombia: implicaciones para las políticas de vacunación. Inf Quinc Epidemiol Nac 2000;5:307-14.

47. Muñoz N, de Vargas $\mathrm{Cl}$. Informe del programa de red de meningitis bacteriana aguda. Inf Quinc Casos Brotes de Enfermedades. IQCB 1996;1:1-4.

48. Agudelo CL, Muñoz N, Sanabria OM, Galindo B, García MJ. Informe de evaluación del programa de meningitis bacteriana aguda de microbiologia, Laboratorio Nacional de Referencia, 1996. Inf Quinc Epidemiol Nac 1997;2:309-11.

49. Ministerio de Salud, Dirección General de Promoción y Prevención, Oficina de Epidemiología. Sistema Alerta Acción. Acumulado 1997. Inf Quinc Epidemiol Nac 1998:3:13.
50. Ministerio de Salud, Dirección General de Promoción y Prevención, Oficina de Epidemiología. Sistema Alerta Acción. Acumulado 1998. Inf Quinc Epidemiol Nac 1999;4:15.

51. Ministerio de Salud, Dirección General de Promoción y Prevención, Oficina de Epidemiologia. Sistema de Vigilancia en Salud Pública (SIVIGILA). Acumulado 1999; Inf Quinc Epidemiol Nac 2000;5:31.

52. Ministerio de Salud, Dirección General de Promoción y Prevención, Oficina de Epidemiología. Sistema de Vigilancia en Salud Pública (SIVIGILA). Acumulado 2000; Inf Quinc Epidemiol Nac 2001;6:15.

53. Ministerio de Salud, Dirección General de Promoción y Prevención, Oficina de Epidemiología. Sistema de Vigilancia en Salud Pública (SIVIGILA), Inf Quinc Epidemiol Nac. 2001;6:29

54. $1^{\text {er }}$. Congreso Mundial de Infectología Pediátrica. Meningitis en Colombía. Etiologia. Reportes locales en población menor a 5 años. México; 1996.

55. Higuera AB, Pastor D, de la Hoz F, Luna M, Gómez O. Efectividad de la vacuna anti-Haemophilus influenzae en neumonias bacterianas. Segundo informe preliminar: 11 de Junio de 2000. Inf Quinc Epidemiol Nac 2000;5:16372

56. Takala AK, Mounrman O, Kleemola M. Preceding respiratory infection predisposing for primary and secondary invasive Haemophilus influenzae type $b$ disease. Pediatr Infect Dis J 1993;12:189-95.

57. Moxon ER. Molecular basis of invasive Haemophilus influenzae type b disease. J infect Dis 1992;165:S77S81.

58. Rubin LG, Moxon ER. Pathogenesis of bloodstream invasion with Haemophilus influenzae type b. Infect Immun 1979;24:102-5.

59. Smith AL, Daum RS, Scheifele DW. Pathogenesis of Haemophilus influenzae meningitis. En: Sell SH, Wright PF, editors. Haemophilus influenzae, New York: Elsevier Science Publishing; 1982 p.89-109.

60. Fothergill LD, Wright J. Influenzal meningitis: the relation of age incidence to the bactericidal power of blood against causal organism. J Immunol 1933;24:27384.

61. Alexander HE, Ellis C, Leidy G. Treatment of typespecific Haemophilus influenzae infections in infancy and childhood. J Pediatr 1942;20:673-98.

62. Robbins JB, Schneerson R, Argaman M. Haemophilus influenzae type $\mathrm{b}$ : disease and immunity in humans. Ann Intern Med 1973;78:259-69.

63. Johnston RB, Anderson P, Newman S. Opsonization and phagocytosis of Haemophilus influenzae type b. En: Sell SH, Karzon DT, editors. Haemophilus influenzae. Nashville, TN: Vanderbilt University Press; 1973. p.99-112. 
64. Kayhty H, Jousimies-Somer $\mathrm{H}$, Peltola $\mathrm{H}$. Antibody response to capsular polysaccharides of groups $A$ and C Neisseria meningitidis and Haemophilus influenzae type b during bacteremic disease J Infect Dis 1981; 143:32-41.

65. Kayhty H, Peltola H, Karank V. The protective level of serum antibodies to the capsular polysaccharide of Haemophilus influenzae type b. J Infect Dis. 1983;147: 1100 .

66. Ambrosino DM, Schiffman G, Gotschlich EC Correlation between $\mathrm{G} 2 \mathrm{~m}(\mathrm{n})$ immunoglcbulin allotype and human antibody response and susceptibility to polysac-charide encapsulated bacteria. J Clin Invest 1975; $75: 1935-42$

67. Pichinchero ME, Insel RA. Relationship between natural occurring human mucosal and serum antibody to the capsular polysaccharide of Haemophilus influenzae type b. J Infect Dis 1983;146:243-8.

68. Tarr PI, Peter G. Demographic factors in the epidemiology of Haemophilus influenzae meningitis in young children. J Pediatr 1978;92:884-88.

69. Fraser DW. Haemophilus influenzae in the community and in the home. En: Sell SH, Wright PF, editors. Haemophilus influenzae. New York: Elsevier Science Publishing; 1982. p.11-22.

70. Janna JN. The epidemiology of invasive Haemophilus influenzae infections in children under five years of age in the Northern Territory: a three-year study. Med $\mathrm{J}$ Aust 1990;152:234-40

71. Ochi SL, Fleming DW, Hightower AW. Primary invasive Haemophilus influenzae type b disease: a population-based assessment of risk factors. J Pediatr 1986;108:887-96

72. Fraser DW, Geil CC, Feldman RA. Bacterial meningitis in Bernadillo County, New Mexico: a comparison with three other American populations. Am J Epidemiol 1974; 100:29-34.

73. Tarr Pi, Peter G. Demographic factors in the epidemiology of Haemophilus influenzae meningitis in young children. J Pediatr 1978;92:884-8.

74. Ward JI, Smith AL. Haemophilus influenzae bacteremia in children with sickle cell disease. J Pediatr 1976;88:261-2

75. Figueroa JE, Densen P. Infectious diseases associated with complement deficiencies. Clin Microbiol Rev 1991:4:359-95.

76. Barlett AV, Zusman J, Daum RS. Unusual presentations of Haemophilus influenzae infections in immunocompromised patients. J Pediatr 1983;102:55-8.

77. Lum MK, Ward JI, Bender TR. Protective influence of breastfeeding on the risk of developing invasive Haemophilus influenzae type b disease [abstract]. Pediatr Res 1982;16:436.
78. Insel RA, Amstey M, Pichinchero ME. Postimmunization antibody to the Haemophilus influenzae type b capsule in breast milk. J Infect Dis 1985;152:407-8.

79. Takala AK, Clements DA. Socioeconomic risk factors for invasive Haemophilus influenzae type b disease. J Infect Dis 1992;165:S11-S15.

80. Istre GR, Conner JS, Broome CV. Risk factors for primary invasive Haemophilus influenzae disease: increased risk from daycare attendance and school age household members. J Pediatr 1985;106:190-5

81. Michelis RH, Shultz WF. The frequency of Haemophilus influenzae infections: analysis of racial and environmental factors. En: Sell SH, Karzon DT editors Haemophilus influenzae. Nashville, TN: Vanderbilt University Press; 1973. p.243-50

82. Estrada $S$, Ospina $S$, Jaramillo $E$, Bustamante $M$, Gallego M, Montealegre N. Resultados bacteriológicos en el líquido cefalorraquideo de pacientes con sospecha clínica de meningitis bacteriana: cuatro años de experiencia. Acta Méd Colomb 1996;21:110-4

83. Kleiman MB, Reynolds JK, Watts NH. Superiority of acridine orange stain in partially treated bacterial meningitis. J Pediatr 1984;104:401-4.

84. Ward JL, Siber GR, Scheifele DW. Rapid diagnosis of Haemophilus influenzae type $\mathrm{b}$ infections by latex particle agglutination and counterimmunoelectrophoresis. J Pediatr 1978;93:37-42.

85. Marcon MJ, Hamoudoi AC, Cannon HJ. Comparative laboratory evaluation of three antigen detection methods for diagnosis of Haemophilus influenzae type b disease. J Clin Microbiol 1984;19:333-7.

86. McGraw TP, Bruckner DA. Sensitivity of commercial agglutination and counterimmunoelectrophoresis methods for the detection of Haemophilus influenzae type b capsular polysaccharides. Am J Clin Pathol 1983; 80:703-6.

87. Spinola SM, Scheaffer CL, Philbrick KB, Gilligan $\mathrm{PH}$. Antigenuria after Haemophilus influenzae type b polysaccharide immunization: a prospective study. J Pediatr 1986;109:835-8.

88. Peltola H. Worldwide Haemophilus influenzae type b disease at the beginning of the $21^{\text {st }}$ century: a global analysis of the disease burden 25 years after the use of the polysaccharide vaccine and a decade after the advent of conjugates. Clin Microb Rev 2000;13:302-17.

89. Sell SHW, Merrill RE, Doyn EO, Zinski EP. Long-term sequelae of Haemophilus influenzae meningitis. Pediatrics 1972;42:206-17.

90. Taylor HG, Mills EL, Ciampi A. The sequelae of meningitis in school-aged children. N Engl J Med 1990; 323:1657-63

91. Ferry PC, Culbetson JL, Cooper JA. Sequelae of Haemophilus influenzae meningitis. En: Sell SH, Wright 
PF, editors Haemophilus influenzae: epidemiology, immunology and prevention of disease. New York: Elsevier Science Publishing; 1982. p.111-7.

92. Ginsburg CM, Howard JB, Nelson JD. Report of 65 cases of Haemophilus influenzae pneumonia. Pediatrics 1979;64:283-6.

93. Shann F. Etiology of severe pneumonia in children in developing countries. Pediatr Infect Dis 1986;5:247-52.

94. Turk DC. Clinical importance of Haemophilus influenzae-1981. En Shell SH, Wright PF, editors. Haemophilus influenzae, epidemiology, immunology and prevention of disease. New York: Elsevier; 1982. p.3-9.

95. Moxon ER. Haemophilus influenzae. En: Mandell, Douglas and Bennett's. Principles and practice of infectious diseases. New York: Churchill Livingstone Inc.; 1995. p.2042.

96. Berenberg W, Kevy S. Acute epiglottitis in childhood: a serious emergency readily recognized at the bedside. N Eng J Med 1958;258:870-4.

97. Jorgensen $\mathbf{J H}$. Update on mechanisms and prevalence of antimicrobial resistance in Haemophilus influenzae. Clin Infect Dis 1992;14:1119-23.

98. Doren GV, Jergensen JH, Thornsberry C. National collaborative study of the prevalence of antimicrobial resistance among clinical isolates of Haemophilus influenzae. Antimicrob Agents Chemother 1998;32: 108-15.

99. Jaramillo E, Estrada S, Vélez L. Resultados de la vigilancia de laboratorio en meningitis bacteriana: ocho años de seguimiento. Acta Méd Colomb 1998; 23:334-8.

100. Muñoz N, Linares M, Agudelo Cl. Susceptibilidad antimicrobiana de Haemophilus influenzae como agente de la meningitis bacteriana aguda y la neumonía. Biomédica 1997;17(Supl1):MI2,109.

101. Feigin RD, McCracken GH Jr, Klein JO. Diagnosis and management of meningitis. Pediatr Infect Dis J 1992; $11: 785 ; 814$

102. Klein JO, Feigin RD, McCracken GH. Report of the task force on diagnosis an management of meningitis. Pediatrics 1986;78:501-5.

103. Jacobs RF, Wright MW, Deskin RL. Delayed sterilization of Haemophilus influenzae type b meningitis with twice-daily ceftriaxone. JAMA 1988; 259:392-4

104. Sirinavin S, Chiemchanya S, Visudhipan P. Cefuroxime treatment of bacterial meningitis in infants and children. Antimicrob Agents Chemother 1984; 25:273-5.

105. Prober $\mathrm{CJ}$. The role of steroids in the management of children with bacterial meningitis. Pediatrics 1995; 95:29-31.
106. Committee of Infectious Diseases, American Academy of Pediatrics. Haemophilus influenzae infections. Red Book 2000. 25 $5^{\text {th }}$ edition. Chicago, IL: American Academy of Pediatrics; 2000.

107. Anderson P, Pichichero ME, Insel RA. Immunization of 2-month old infants with protein-coupled oligosaccharides derived from the capsule of Haemophilus influenzae type b. J Pediatr 1985;107: 346-51.

108. Kaythy H, Karanko V, Peltola H, Makela PH. Serum antibodies after vaccination with Haemophilus influenzae type b capsular polisaccharide and responses to reimmunization: no evidence of immunologic tolerance or memory. Pediatrics 1984;74: 857-65.

109. Milstien JB, Gross TP, Kuritsky JN. Adverse reactions reported following receipt of Haemophilus influenzae type b vaccine: an analysis after 1 year of marketing. Pediatrics 1987;80:270-4.

110. Lansteiner K. The Specificity of serologic reactions. Cambridge: Harvard University Press; 1945. Reprinted by Dover Publications, New York; 1962.

111. Schneerson R, Barrera O, Sutton A, Robbins JB. Preparation, characterization, and immunogenicity of Haemophilus influenzae type b polysaccharide-protein conjugates. J Exp Med 1980;152:361-76.

112. Ward J, Zangwill K. Haemophilus influenzae vaccines. En: Plotkin SA, Orenstein WA, editors. Vaccines. Third Edition. Philadelphia: W.B. Saunders Company; 1999. p.195-210.

113. Anderson P. Antibody responses to Haemophilus influenzae type b diphteria toxin induced by conjugates of oligosaccharides of the type b capsule with nontoxic protein CRM $_{197}$. Infect Immun 1983;39:233-38.

114. Tai JY, Vella PP, McLean AA. Haemophilus influenzae type $b$ polysaccharide-protein conjugate vaccine. Proc Soc Exp Biol Med 1987;184:154-61.

115. Vella PP, Staub JM, Armstrong J. Immunogenicity of a new Haemophilus influenzae type b conjugate vaccine (meningococcal protein conjugate) (PedvaxHIB). Pediatrics 1990;85:668-75.

116. Centers for Disease Control and Prevention. Recommendations for use of Haemophilus influenzae conjugate vaccines and a combined diphteria, tetanus, pertussis, and Haemophilus type b vaccine. Recommendations of the Advisory Committee on Immunization Practices (ACIP). 1993;42 (RR-13):115.

117. Centers for Disease Control and Prevention. Joint statement for thimerozal Use in Vaccines. MMWR 2000;49;622-31.

118.Peltola H, Kilpi T, Anttila M. Rapid disappearance of Haemophilus influenzae type $\mathrm{b}$ meningitis after routine 
childhood immunization with conjugated vaccines Lancet 1992;340:592-4

119. Centers for Disease Control and Prevention. Progress towards elimination of Haemophilus influenzae type $b$ disease among infants and children - United States, 1987-1995. MMWR 1996;45:901-6.

120. Centers for Disease Control and Prevention. National, state and urban area vaccination coverage levels among children aged $19-35$ months. United States, January-December 1995. MMWR 1997;46:17682.

121.Cochi SL, Fleming DW, Hightower AW, Limpakarnjanarat K, Facklam RR, Smith JD, et al. Primary invasive Haemophilus influenzae type b disease: a population-based assessment of risk factors. J Pediatr 1986;108-887-96.

122. Barbour ML. Conjugated vaccines and the carriage of Haemophilus influenzae type b. Emerg Infect Dis 1996;3:176-82.

123. Lagos R, Valenzuela MT, Levine OS, Losonsky A, Erazo A, Wasserman SS, Levine MM. Economisation of vaccination against Haemophilus influenzae type $\mathrm{b}$ : a randomized trial of immunogenicity of fractional-dose and two-dose regimes. Lancet 1998; 351:1472-6.

124. Asociación Española de Pediatría, Comité Asesor de Vacunas (1998-2002). Esquemas del plan ampliado de vacunación en paises latinoamericanos. En: Tregnaghni $M$, Ceballos $A$, editores. Adaptación latinoamericana del manual de vacunas en pediatria. Madrid, España: Asociación Española de Pediatria; 2001.

125. Lagos R, Valenzuela MT, Levine OS, Losonsky A, Erazo A, Wasserman SS, Levine MM. Large scale, postlicensure, selective vaccination of Chilean infants with PRP-T conjugated vaccine: practicality and effectiveness in preventing invasive Haemophilus influenzae type b infections. Pediatr Infect Dis J 1996; $15: 216-22$
126. Peltola H. Haemophilus influenzae type b disease and vaccination in Latin America and the Caribbean. Pediatr Infect Dis J 1997;16:780-87.

127. Landaverde M, Di Fabio JL, Ruocco G, Leal I, de Quadros C. Introducción de la vacuna conjugada contra Hib en Chile y Uruguay. Rev Panam Salud Pública 1999:5:200-6.

128. Ruocco G, Curto S, Savro M, Lavrani H, Frocht R. Vacunación contra Haemophilus influenzae tipo b en Uruguay: experiencia e impacto. Rev Panam Salud Pública 1999;5:197-99.

129. Caro-Cassali M, Vargas-Campos A, MohsVillalta, Arguedas-Mohs A. Enfermedad sistémica por Haemophilus influenzae tipo b en el Hospital Nacional de Niños, un año después de la introducción de la vacuna conjugada. Bol Med Hosp Infant Mex. 1995;52: 426-30.

130. Odio CM, Mohs E, Ramirez L, Herrera M, Faingezicht. Pediatr Res 1992;31:98.

131. Kayty H, Peltola H, Karanko V. The protective level of serum antibodies to the capsular polysaccharide of Haemophilus influenzae type b. J Infect Dis 1983;147: 1100.

132. Agudelo $\mathrm{Cl}$, Muñoz N, De la $\mathrm{Hoz} \mathrm{F}$, Laboratorios de Salud Pública. Evaluación rápida del impacto de la vacuna contra Haemophilus influenzae serotipo b en Colombia. Pan Am J Public Health 2000;8:181-4.

133. Ministerio de Salud, Programa Ampliado de Inmunizaciones. Coberturas de vacunación por biológico y departamento, 2000. Programa MIPAISOFII-02/00.

134. Steinhoff $\mathbf{M}$. Haemophilus influenzae type b infections are preventable everywhere. Lancet 1997; 349:1186-7.

135. Restrepo B, Olaya A, Upegui G, Aguirre C, Carrizosa J. Estudio de los costos de la atención y años de vida perdidos por muerte por meningitis por Neisseria meningitidis y Haemophilus influenzae. Rev Epidemiol Antioquia 1998;23:57-64. 